\title{
LANDFALLING TROPICAL CYCLONE RESEARCH PROJECT (LTCRP) IN CHINA
}

Yihong Duan, Qilin Wan, Jian Huang, Kun Zhao, Hui Yu, Yuging Wang, Dajun Zhao, Jianing Feng, Jie Tang, Peiyan Chen, Xiaogin lu, Yuan Wang, Jianyin liang, liguang Wu, Xiaopeng Cui, Jing Xu, and Pak-Wai Chan

This article presents an overview of a 10-yr landfalling tropical cyclone research project in China together with highlights of new findings and technical developments as well as planned future efforts.

C hina suffers disasters induced by landfalling tropical cyclones (TCs) more frequently than anywhere else in the world (Q. Zhang et al.2009). Dramatic structure and intensity changes regularly occur during TC landfall, and they are highly challenging for TC forecasting and disaster prevention (Elsberry et al. 2013). TCs entailed an annual economic loss of approximately RMB 28.7 billion [equivalent to about $\$ 4.1$ billion (U.S. dollars)] and an annual loss of life of approximately 470 on average from 1983 to 2006 in China (Q. Zhang et al. 2009). Prediction failure of these structure and intensity changes is detrimental to disaster preparedness and evacuation and in some cases even aggravates the
Affiliations: Duan, D. Zhao, Feng, and Xu-State Key Laboratory of Severe Weather, Chinese Academy of Meteorological Sciences, China Meteorological Administration, Beijing, China; WAN, HUANG, AND LIANG - Guangdong Provincial Key Laboratory of Regional Numerical Weather Prediction, Institute of Tropical and Marine Meteorology, China Meteorological Administration, Guangzhou, China; K. ZHAO AND YUAN WANG-Key Laboratory of Mesoscale Severe Weather, Ministry of Education of China, and School of Atmospheric Sciences, Nanjing University, Nanjing, China; Yu, TANG, Chen, AND Lu-Shanghai Typhoon Institute, China Meteorological Administration, Shanghai, China; YUQING WANG-State Key Laboratory of Severe Weather, Chinese Academy of Meteorological Sciences, China Meteorological Administration, Beijing, China, and International Pacific Research Center, and Department of Atmospheric Sciences, School of Ocean and Earth Science and Technology, University of Hawai'i at Mānoa, Honolulu, Hawaii;
Wu-Department of Atmospheric and Oceanic Sciences, and Institute of Atmospheric Sciences, Fudan University, Shanghai, China; Cul-Key Laboratory of Cloud-Precipitation Physics and Severe Storms (LACS), Institute of Atmospheric Physics, Chinese Academy of Sciences, Beijing, China; CHAN-Hong Kong Observatory, Hong Kong, China

CORRESPONDING AUTHOR: Prof. Yuqing Wang,

yuqing@hawaii.edu

The abstract for this article can be found in this issue, following the table of contents.

DOI:10.|I75/BAMS-D-18-024I.I

In final form 28 September 2019 (C)2019 American Meteorological Society

For information regarding reuse of this content and general copyright information, consult the AMS Copyright Policy. 
disaster. The national Landfalling Tropical Cyclone Research Project (LTCRP) in China was conceived and got funded in 2009. The main objectives of the project are to investigate the characteristics of structure and intensity changes during TC landfall and associated physical mechanisms and to develop new technology to advance the forecast ability of landfalling TCs.

Drastic structure and intensity changes generally occur before a TC makes landfall in China due to the influences of underlying ocean features, land-ocean contrast, orography, and atmospheric circulations (Duan et al. 2014). For instance, some TCs suddenly intensify or weaken and even dissipate in addition to sudden track changes, including sharp turning, unexpected acceleration, and meandering often observed prior to landfall of a TC. These drastic structure and intensity changes are usually difficult to forecast and thus often cause great difficulties in disaster preparedness and evacuation. Tornadoes, squall lines, and thunderstorms frequently occur during TC landfall. The circulations and remnants of some post-landfalling TCs can remain well organized for quite a long time, causing severe disasters, including dramatic inundation, river overflowing, dam bursts, and mudslides (Chen et al. 2010). However, physical mechanisms governing the above anomalous structure and intensity changes and the associated mesoscale convective systems during TC landfall have not been well understood, and the corresponding forecast ability needs to be improved with well-coordinated advanced technical developments (Elsberry et al. 2013).

The national LTCRP in China has been ongoing for about 10 years and includes three main components: field experiment, scientific research, and technical developments. The landfalling TC field experiment was designed and has been conducted to collect data from targeted landfalling TCs. The second component of the project is scientific understanding using data from field experiments. The third component is advanced technical developments. The overall mission of the project is to understand the physical processes associated with drastic structure and intensity changes during TC landfall; to improve the ability to predict track, intensity, and precipitation of landfalling TCs; and to develop methods to assess

\section{The Landfalling Typhoon Observing System}

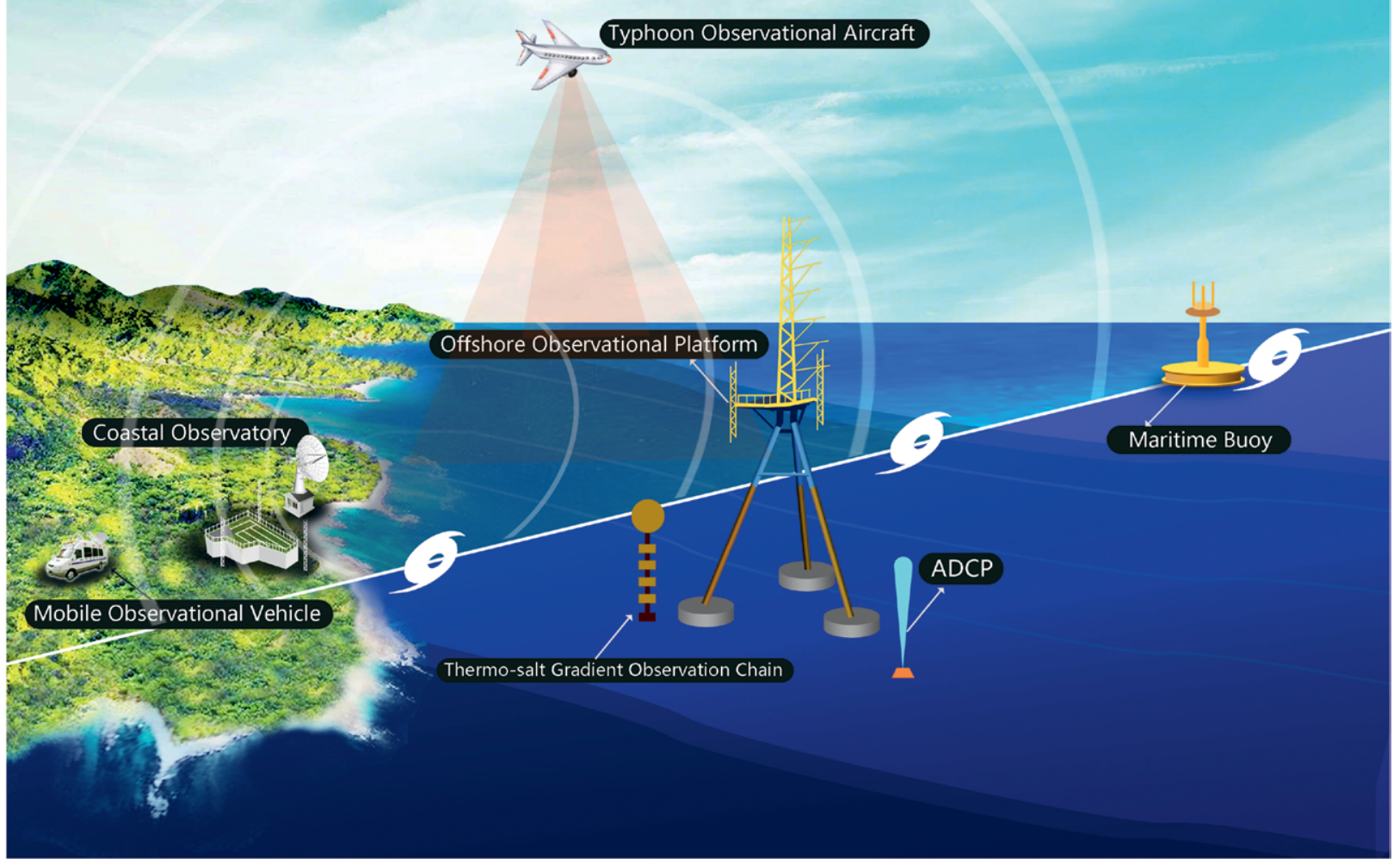

FIG. I. Schematic diagram of sea-land-air integrated TC observation at the Bohe Marine Meteorological Science Experiment Base. 
TABLE I. List of apparatus for integrated marine observational platform.

\begin{tabular}{|c|c|c|c|c|}
\hline No. & Equipment name & Model and origin & Quantity & $\begin{array}{c}\text { Year of } \\
\text { operation }\end{array}$ \\
\hline 1 & Eddy covariance system & $\begin{array}{l}\text { Gill Windmaster Pro, United Kingdom/LI-COR } \\
7500 \text {, United States }\end{array}$ & 2 & $2008-$ \\
\hline 2 & $3 \mathrm{D}$ research anemometer & Gill R3-50, United Kingdom & 5 & $2012-$ \\
\hline 3 & $\begin{array}{l}\text { Meteorological element gradient observation } \\
\text { system }\end{array}$ & $\begin{array}{l}\text { RM Young 05106, United States/Vaisala HMP45C, } \\
\text { Finland }\end{array}$ & 5 & $2008-$ \\
\hline 4 & Four-component net radiometer & Kipp \& Zonen CMP22/CGR4, CNR-I, Netherlands & 1 & $2010-$ \\
\hline 5 & Enhanced precipitation identifier & OTT Pasrsivel2, United States & 1 & $2008-$ \\
\hline 6 & Rain gauge & RM Young 050202, United States & 1 & $2008-$ \\
\hline 7 & Infrared temperature transducer & Everest Interscience 4000.3ZL, United States & 1 & $2008-$ \\
\hline 8 & Thermo-salt gradient observation system & ALEC INFINITY-CTW, Japan & 3 & $2011-13$ \\
\hline 9 & Sea temperature gradient observation chain & RBRsolo T, Canada & 4 & $2017-$ \\
\hline 10 & Acoustic Doppler current profiler & FLOWQUEST 1000, United States & 1 & $2017-$ \\
\hline II & Particle drop spectrometer & DMT FHS-100, United States & 1 & $2016-$ \\
\hline 12 & Fog monitor & DMT FM-100, United States & 2 & $2016-$ \\
\hline
\end{tabular}

the impact of TC-induced disasters. Specifically, the project has been focusing on the characteristics and physical processes related closely to drastic structure and intensity changes during landfall, including the involved large-scale environmental conditions and mesoscale systems, air-land-sea interactions, satellite and radar data assimilation and applications, and the development of an air-land-sea coupled TC forecast model.

There are two phases of the LTCRP. The first phase (2009-14) focused on the study of sudden changes in track and intensity of nearshore TCs making landfall over mainland China, including the air-sea interaction in the coastal shallow water in the continental shelf. The second phase (2015-19) has been focusing on landfalling processes of TCs over mainland China, in particular the boundary layer and cloud/ precipitation processes and forecast technical developments. Through the LTCRP, considerable progress has been made in the understanding of air-sea-land interactions during TC landfall and their effects on landfalling TC track, structure, and intensity changes based on data obtained from field experiments, and in the developments of advanced data assimilation techniques and ensemble forecast system to improve forecasts of landfalling TCs, including their tracks, structure and intensity changes, torrential rainfall, strong winds, and corresponding disasters. In addition, several methods have also been developed to assess impacts of landfalling TCs in mainland China under this project. This article provides an overview of the LTCRP with some preliminary research findings and technical developments being highlighted.
FIELD EXPERIMENTS. An overview of the observing systems. The understanding of physical processes within the marine-atmospheric boundary layer and the precipitation microphysical processes and the better representation of those physical processes in numerical models are key to improving numerical predictions of TC track, intensity, and structure changes. Landfalling TC field experiments have been conducted to collect data from targeted landfalling TCs under this project. The data collected have been used to understand physical processes of landfalling TCs, to verify performance of numerical prediction models, and to improve the model initial conditions through data assimilation. To achieve the scientific goal of this project, a four-dimensional (one time and three space dimensions) meteorological observing system has been established along the coast of Guangdong, South China, based on the meteorological observational network of the China Meteorological Administration (CMA).

The observational system of the marine atmospheric boundary layer mainly consists of facilities at Bohe Marine Meteorological Science Experiment Base in the western part of Guangdong Province (Fig. 1), the maritime observational platform, the 100-m height observational tower located at Zhizai Island, the maritime buoy, and the mobile wind profile radar observational vehicles. The maritime observational platform, an offshore fixed platform which is $6.5 \mathrm{~km}$ from the coastline, provides information on the near-surface layer, including three-dimensional (3D) wind, temperature, and humidity fluctuation and vertical gradient of their distributions (Table 1). A submarine cable serves for power supply and data 
transfer. As a supplement to the maritime observational platform, the turbulence and sea-air fluxes are also measured by the instruments installed at the 100-m height observational tower.

The sea state is mainly measured by nearshore acoustic Doppler current profiler and thermo-salt gradient observation chain $6.5 \mathrm{~km}$ from coastline and the maritime buoy $100 \mathrm{~km}$ from coastline. The maritime buoy is a disc buoy with a nominal diameter of $10 \mathrm{~m}$ equipped with a variety of instruments for measuring meteorological and marine environmental elements, including waves, surface currents, wind, temperature, humidity, air pressure, and precipitation (Table 2). The mobile wind profile radar vehicle provides measurements of the atmospheric boundary layer over land in landfalling TCs. It can measure not only local weather elements, such as temperature, humidity, air pressure, and precipitation, but also vertical wind; 3D high-frequency wind speed variation and turbulence near the land surface; and profiles of wind, temperature, and humidity detected by wind profiler and microwave radiometer. In addition, several other scattered 3D boundary layer tower observations were also installed in Fujian and Zhejiang Provinces along the southeast coast of mainland China.

The key dynamical and microphysical structure of TCs are mainly observed by two aircraft, the mobile C-band dual-polarization radar vehicle, operational S-band dual-polarization radar, and the cloud physics and heavy precipitation observational base (Table 3). The CMA's artificial precipitation enhancement aircraft and Hong Kong Observatory's (HKO) typhoon

\begin{tabular}{|c|c|c|c|c|}
\hline No. & Equipment name & Origin and model & Quantit & $\begin{array}{c}\text { Year of } \\
\text { operation }\end{array}$ \\
\hline 1 & Wind profiler & WP3, China & I & $2013-$ \\
\hline 2 & C-band dual polarization weather radar & 3836A, China & 1 & $2017-$ \\
\hline 3 & 2D-video disdrometer & JOANNEUM 2DVD_OP_2009, Austria & 1 & $2016-$ \\
\hline 4 & Ku-band Micro Rain Radar & METEK MRR-2, Germany & 1 & $2016-$ \\
\hline 5 & Enhanced precipitation identifier & OTT PARSIVEL2, Germany & 1 & $2013-$ \\
\hline 6 & Ceilometer & Vaisala CL5I, Finland & 1 & 2017- \\
\hline 7 & Fog monitor & DMT FM-I20, United States & 1 & $2017-$ \\
\hline 8 & Total sky imager & CP-2000, China & I & $2017-$ \\
\hline 9 & Lightning locator & ADTD, China & 1 & $2015-$ \\
\hline 10 & Particulate mass concentration detector & LGH-0IE/B, China & 1 & $2015-$ \\
\hline 11 & Scanning mobility particle sizer & TSI SMPS 3936, United States & 1 & $2016-$ \\
\hline 12 & Aerodynamic Particle Sizer (APS) spectrometer & TSI APS-332I, United States & 1 & $2016-$ \\
\hline 13 & Cloud condensation nuclei counter & DMT CCN-100, United States & 1 & $2016-$ \\
\hline 14 & Aerosol laser lidar & Everise EV-lidar-CAM, United States & 1 & $2016-$ \\
\hline 15 & Atmospheric electric field instrument & LT-100, United States & 1 & $2017-$ \\
\hline 16 & GPS/Met & NET-RS, United States & 1 & $2008-$ \\
\hline 17 & Ka-band millimeter radar & Ka, China & 1 & $2013-$ \\
\hline 18 & C-band frequency modulated continuous wave radar & C-FMCW, China & 1 & $2013-$ \\
\hline 19 & X-band phased array weather radar & XPAR, China & 1 & $2013-$ \\
\hline 20 & X-band dual-polarization radar & YLDI-D, China & 1 & $2016-$ \\
\hline
\end{tabular}




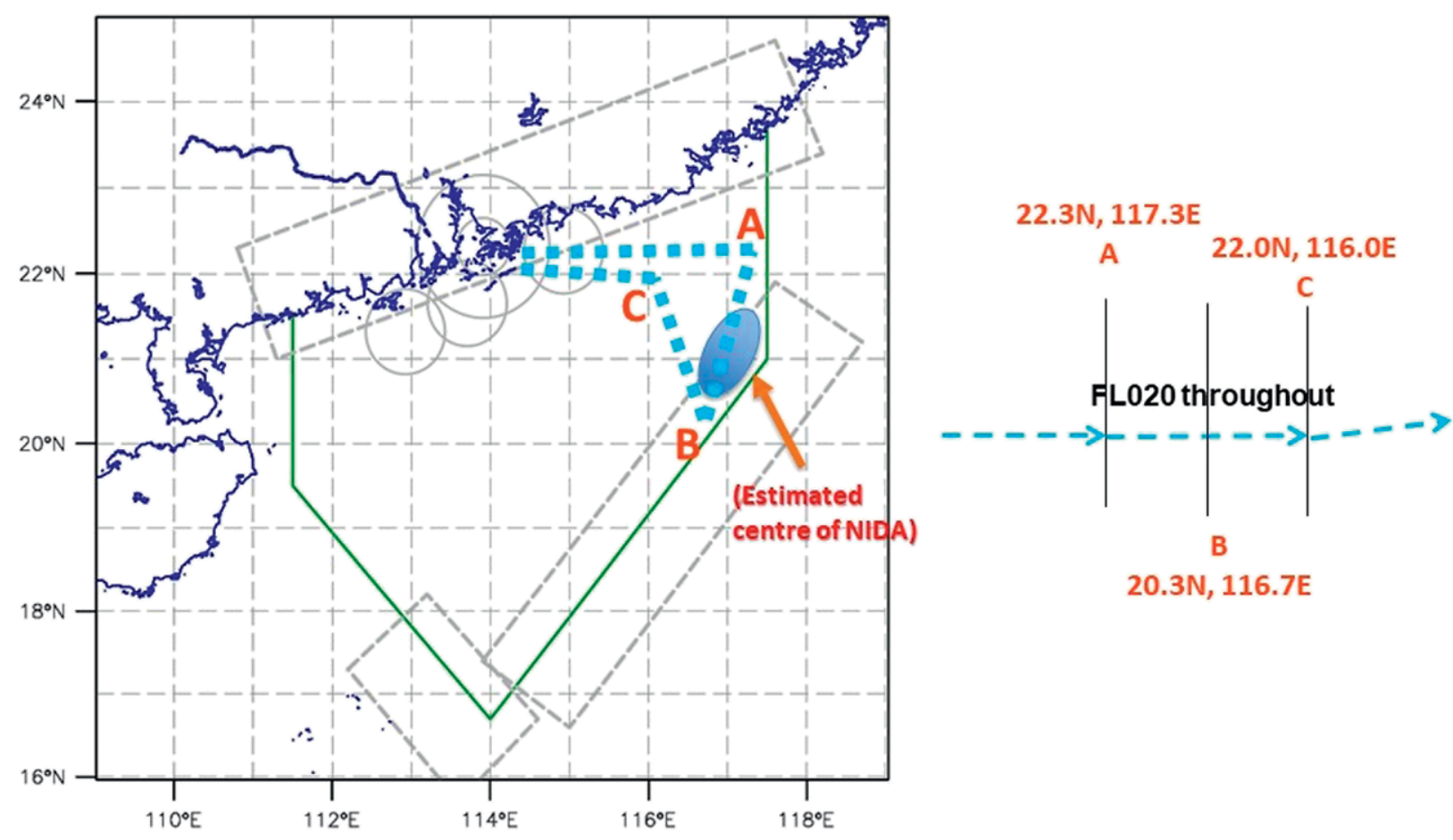

FIG. 2. The flight information region of Hong Kong (green line) and the planned flight for Typhoon Nida (20I6) by the HKO's typhoon observational aircraft on I Aug 2016.

observational aircraft, both of which carry the cloud microphysical observing systems, are used to measure the 3D in situ cloud/rain drop spectrum. There are microphysics probes on the artificial precipitation enhancement aircraft, which can collect in situ microphysical measurements above the freezing level. The HKO typhoon observational aircraft is a Bombardier Challenger 605, which is a jet with two engines and that flies up to $30,000 \mathrm{ft}$ with a period of $5 \mathrm{~h}$ in the flight information region of Hong Kong (Fig. 2). The measured cloud microphysical parameters include cloud condensation nuclei, cloud droplet size and distribution, precipitation rate, and water contents of raindrops and ice crystals. In addition, the airborne meteorological element detection system and the dropsonde system are used to measure the dynamical fields in the targeted area of a landfalling TC, including the wind direction and speed, temperature, humidity, and vertical profile of pressure. On the ground, the disdrometers are used as auxiliary detection means to provide the in situ measurements of raindrop spectrum.

The S-/C-band dual-polarization weather radars and the vertical cloud/rain radars are the main instruments that provide remotely sensed estimates of cloud microphysics properties. The vertical cloud/ rain radars can provide the profiles of cloud/rain drop spectrum when a TC passes over the stations. The dual-polarization radars detect the 3D dynamical and microphysical structures of TCs, such as the radial velocity, the size distribution, and the phase type of precipitation particles. A mobile C-band dual-polarization radar vehicle is employed to observe the targeted area of a TC after landfall, which is usually preset based on the track forecast of a targeted TC.

Coordinated field experiments, data management, and sharing policy. The field experiment of landfalling TCs started to operate since 2008 and has been coordinated by the Chinese Academy of Meteorological Sciences (CAMS), Guangdong Meteorological Service, Guangzhou Institute of Tropical and Marine Meteorology of CMA, Shanghai Typhoon Research Institute of CMA, and Nanjing University. The experiment makes full use of the Guangdong Meteorological Service station network and two field observational and experimental bases. The field experiment has been supported by both the CMA's typhoon observation and experiment project and the National Basic Research and Development Project (973 program) of China.

A field campaign is often planned and prepared if a TC is forecasted to potentially make landfall in the experiment region (Fig. 3) in $48 \mathrm{~h}$. Observations started to fully operate in $24 \mathrm{~h}$ prior to landfall of a targeted TC, thus including the prelandfall stage of TCs over 


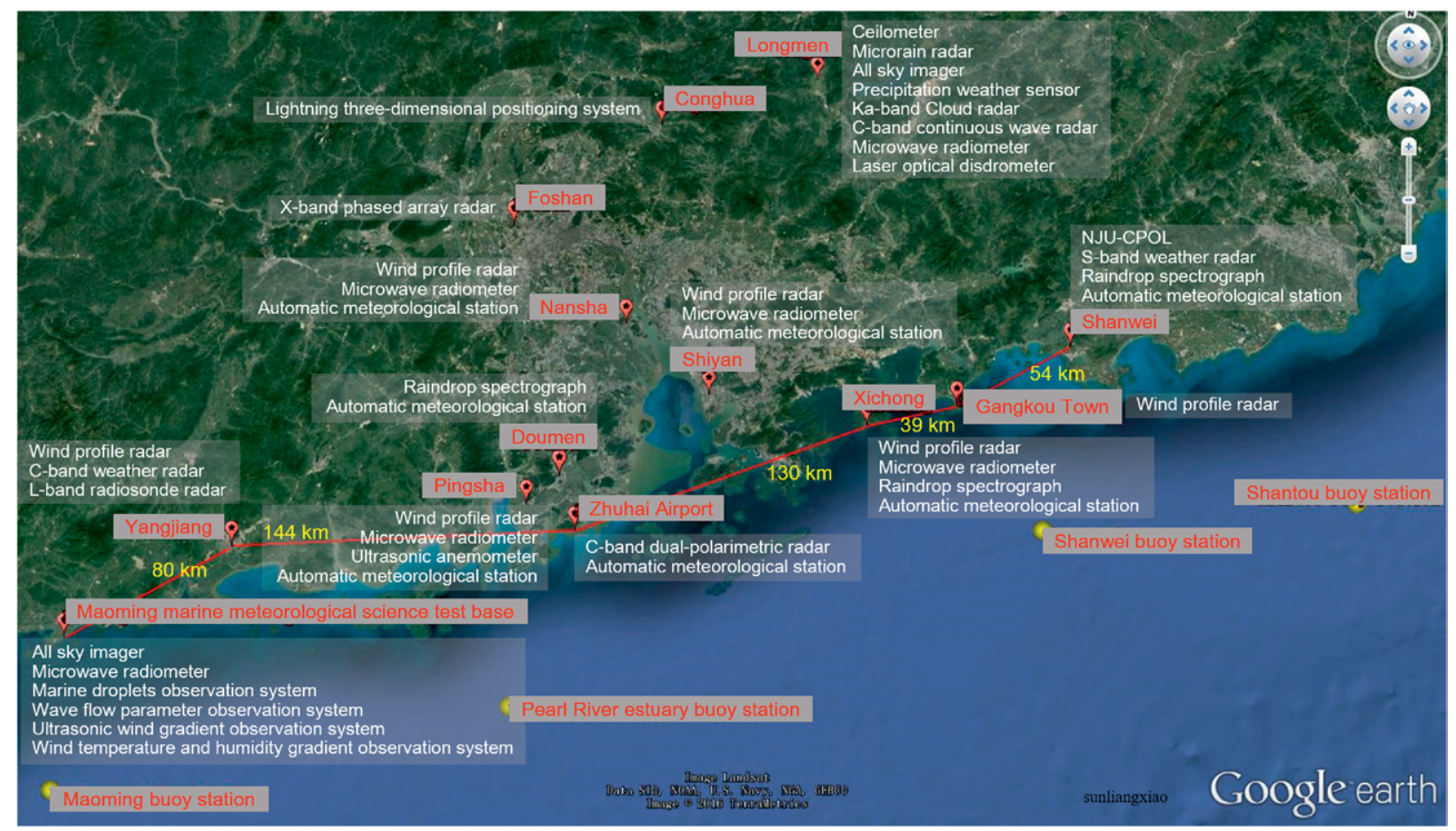

FIG. 3. The experimental area and ground-based sites and equipped instruments of landfalling tropical cyclone field campaigns. Shown is also the distribution of multiple coastal observational instruments in the northern South China Sea during the landfalling period of Typhoon Nida (2016).

the coastal oceans. During the 11-yr period 2008-18 (including the pre-experiment in 2018), the field experiment targeted $24 \mathrm{TCs} /$ typhoons in total with the first-hand observational data obtained (Table 4). The main observational data obtained during these field campaigns are listed in Table 5.

Under this project, a TC Landfalling Process Field Science Experiments Database (TCLPFieldSED) was constructed, which archived the real-time

\begin{tabular}{|ll|}
\hline $\begin{array}{l}\text { TABLE } \\
\text { landfalling typhoon field campaigns } \\
\text { during }\end{array}$ \\
\hline Year & TC name 18. \\
\hline 2008 & Kammuri, Hagupit \\
2009 & Molave, Goni, Morakot, Koppu \\
2010 & Chanthu, Lionrock, Fanapi, Megi \\
2011 & Nock-ten, Nesat \\
2012 & Saola, Haikui, Kai-Tek \\
2013 & Utor \\
2014 & Rammasun, Kalmaegi \\
2015 & Kujira, Mujigae \\
2016 & Nida \\
2017 & Hato, Khanun \\
2018 & Mangkhut \\
\hline
\end{tabular}

observations from all field campaigns, records of TCs experiencing sudden track and intensity changes, retrieved data, and global reanalysis data using SQL server in 2012. All data are stored in the form of tables. TCLPFieldSED includes 11 tables for field observations in East China and 197 tables for field observations in South China, 6 tables for records of TCs experiencing sudden track and intensity changes, 14 tables for satellite and radar observations, 7 tables for global reanalysis data, and 4 tables for metadata. The total amount of data is about 1 TB. Meanwhile, the field experiment database includes measurements from 24 TCs' field campaigns, conventional observations, and satellite and radar observations, such as atmospheric soundings, surface attributes, sea surface attributes, precipitation, temperature, water vapor, and so on. In addition, the metadata extraction for each dataset and the normalized database structure have been established.

Based on the TCLPFieldSED, a TC Science Data Sharing Platform was built up using Browse/Server architecture. Data retrieving, browsing, and downloading can be carried out via this platform. Keyword query and data preview functions based on TC sequential number, year, observational elements, time range, and other combinations are available in this system. All TC observational data can be accessed 
TABLE 5. Main observational platforms and observed items for landfalling TCs.

\section{Platform Monitoring Observation}

category range platform

\begin{tabular}{|c|c|c|c|}
\hline \multirow{2}{*}{ 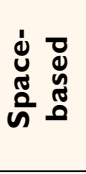 } & \multirow{2}{*}{$\begin{array}{l}\text { Coast, } \\
\text { offshore, } \\
\text { open sea }\end{array}$} & $\begin{array}{l}\text { Fengyun-4 } \\
\text { satellite }\end{array}$ & $\begin{array}{l}\text { Multichannel scanning imagery } \\
\text { radiometer, GIIRS }\end{array}$ \\
\hline & & $\begin{array}{l}\text { Gaofen-4 } \\
\text { satellite }\end{array}$ & $\begin{array}{l}\text { Full-color/multispectral camera, medium } \\
\text { wave infrared camera }\end{array}$ \\
\hline \multirow{3}{*}{ 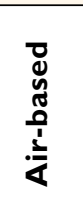 } & \multirow{3}{*}{$\begin{array}{l}\text { Coast, } \\
\text { offshore, } \\
\text { open sea }\end{array}$} & \multirow{3}{*}{$\begin{array}{l}\text { Typhoon } \\
\text { detection } \\
\text { aircraft }\end{array}$} & $\begin{array}{l}\text { Meteorological element detection system } \\
\text { Cloud microphysical detection system }\end{array}$ \\
\hline & & & Droppable sounding system \\
\hline & & & Hydrological element sensor \\
\hline
\end{tabular}

Offshore Marine Meteorological element sensor

(100 km from meteorological

the shore) buoy Hydrological element sensor

Marine automatic station

Eddy covariance system

Near-sea-surface turbulent gradient

observation system

Offshore Maritime

$(6.5 \mathrm{~km}$ from observation

shore)

platform

Acoustic Doppler current profiler

Temperature-salinity gradient chain

Droplet spectrometer, fluxpam
Meteorological element gradient

observation system

Four-component radiometer

Raindrop spectrometer

Offshore Island-based

$(5 \mathrm{~km}$ from $100 \mathrm{~m}$

the shore)

observation

tower

\begin{tabular}{|c|c|}
\hline $\begin{array}{l}\text { Coast, } \\
\text { offshore }\end{array}$ & $\begin{array}{l}\text { Coastal } \\
\text { observation } \\
\text { field }\end{array}$ \\
\hline
\end{tabular}

Coast $\quad \begin{aligned} & \text { Coastal } \\ & \text { observation } \\ & \text { field }\end{aligned}$

Mobile wind profiler radar observation

Coast, vehicle

inland
Eddy covariance system, meteorological element gradient observation system

C-band dual-polarization radar

X-band wave observation radar

Ground wave radar

Boundary layer wind profile/wind lidar

Microwave radiometer

GPS sounding system

Ceilometer

Total sky imager

Eddy covariance system

One-dimensional raindrop spectrometer

Island automatic station Boundary layer wind profiler radar

GPS sounding system

Rocket sounding system (new)

Video sounding system (new)

Portable automatic station

Ultrasonic anemometer for strong wind
Main observed elements and parameters

Multispectral, high-precision surface cloud structure observation data and images; vertical structure of atmospheric temperature and humidity parameters Refined dynamical information of cloud structure and its evolution

Wind, temperature, humidity, and air pressure

Cloud droplet spectrum

Vertical profiles of wind, temperature, humidity, and air pressure

Sea surface wave, current speed and direction, temperature, and salinity

Wind, temperature, humidity, pressure, precipitation, etc., near the sea surface

Sea surface wave, current speed and direction, temperature, and salinity

Six elements including near-sea-surface wind, temperature, humidity, air pressure, and precipitation

Sea-air interface momentum, heat and water vapor flux

Turbulent structure and momentum transfer mode in the strong wind boundary layer

Wave height, wave direction, wave spectrum, current velocity, and profile

Vertical gradients of temperature and salinity in the marine boundary layer

Marine droplet spectrum, vertical flux

Vertical gradient distribution of near-sea-surface wind speed and direction, temperature, and humidity

Downward and upward shortwave and longwave radiation and net radiative flux

Precipitation particle diameter, velocity, distribution density, rain intensity, cumulative rainfall

Momentum, heat and water vapor flux at sea-air interface, and gradient distributions of wind, temperature, and humidity

Precipitation particle size, distribution, phase type, and other parameters

Sea surface reflectivity, wave height, wave direction, wavelength, current speed and direction

Sea surface reflectivity, wave height, wave direction, wavelength, current speed and direction Low-level 3D high-frequency wind speed

Vertical profiles of atmospheric temperature, humidity, and liquid water content

Vertical profiles of atmospheric wind, temperature, and humidity

Cloud base height

Cloud cover, sky conditions

Coastal momentum, heat and water vapor flux

Precipitation particle diameter, velocity, distribution density,

rain intensity, cumulative rainfall

Wind, temperature, humidity, air pressure, and precipitation Atmospheric boundary layer wind profile

Vertical profiles of atmospheric wind, temperature, and humidity

Atmospheric wind, temperature, and humidity profiles

Peripheral cloud droplet spectrum

Wind, temperature, humidity, pressure, and precipitation

High-frequency 3D wind speed

Mobile

C-band dual-

polarization

radar vehicle
C-band dual-polarization radar

Precipitation particle size, distribution, phase type, etc. 


\begin{tabular}{|c|c|c|c|c|c|}
\hline Instrument & Duration & Spatial coverage & $\begin{array}{l}\text { Temporal } \\
\text { resolution }\end{array}$ & Available fields & Contacts \\
\hline $\begin{array}{l}\text { Wave } \\
\text { observation } \\
\text { radar }\end{array}$ & $\begin{array}{l}\text { 0025:13 UTC I8 Sep- } \\
\text { 2355:16 UTC } 20 \text { Sep } 2010\end{array}$ & $\begin{array}{l}\text { Single point observation } \\
\text { of Bohe in Guangdong }\end{array}$ & $3 \min$ & $\begin{array}{l}\text { Significant wave height, peak period, } \\
\text { average wave period, wave crest } \\
\text { length, surge period, surge length, } \\
\text { surge direction, wind wave periods, } \\
\text { wind wavelength, wind wave } \\
\text { direction, surface current velocity, } \\
\text { surface current direction, maximum } \\
\text { wave height, and quality index }\end{array}$ & STI/CMA \\
\hline $\begin{array}{l}\text { Wind-profile } \\
\text { radar }\end{array}$ & $\begin{array}{l}\text { 0025:13 UTC I8 Sep- } \\
\text { 2355:16 UTC } 20 \text { Sep } 2010\end{array}$ & $\begin{array}{l}3 \text { single point obser- } \\
\text { vations of Shenzhen, } \\
\text { Shantou, and Bohe in } \\
\text { Guangdong }\end{array}$ & $30 \mathrm{~min}$ & $\begin{array}{l}\text { Height, temperature, virtual tem- } \\
\text { perature, wind speed, and wind } \\
\text { direction }\end{array}$ & STI/CMA \\
\hline $\begin{array}{l}\text { GPS } \\
\text { sounding }\end{array}$ & $\begin{array}{l}\text { 1817:05 UTC } 19 \text { Sep- } \\
\text { 0035:39 UTC 2I Sep 2010 }\end{array}$ & $\begin{array}{l}\text { Single point observation } \\
\text { in Shantou of Guangdong }\end{array}$ & $3 \mathrm{~h}$ & $\begin{array}{l}\text { Temperature, relative humidity, } u \\
\text { component, } u \text { component, height, } \\
\text { dewpoint, pressure, longitude, and } \\
\text { latitude }\end{array}$ & STI/CMA \\
\hline $\begin{array}{l}\text { Microwave } \\
\text { radiometer }\end{array}$ & $\begin{array}{l}\text { 000I:28 UTC } 20 \text { Sep- } \\
\text { 0404:16 UTC 2I Sep 20I0 }\end{array}$ & $\begin{array}{l}\text { Single point observation } \\
\text { in Shantou of Guangdong }\end{array}$ & $1.5 \mathrm{~min}$ & $\begin{array}{l}\text { Temperature, vapor density, liquid, } \\
\text { and relative humidity }\end{array}$ & STI/CMA \\
\hline Eddy flux & $\begin{array}{l}\text { 0000:00 UTC I8 Sep- } \\
\text { 2359:00 UTC } 21 \text { Sep } 2010\end{array}$ & $\begin{array}{l}\text { Single point observation } \\
\text { in Bohe of Guangdong }\end{array}$ & $0.1 \mathrm{~s}$ & $\begin{array}{l}\text { u component, } u \text { component, } z \\
\text { component, } \mathrm{CO}_{2}, \mathrm{H}_{2} \mathrm{O} \text {, wind } \\
\text { speed, wind direction, virtual } \\
\text { temperature, and pressure }\end{array}$ & STI/CMA \\
\hline
\end{tabular}

by and shared with researchers and forecasters via the internet. During April 2010 and January 2019, the shared data provided offline to the project users reached $2 \mathrm{~TB}$. Through this platform, users can browse and access the data they want by different query criteria. For example, if one queries the field observations of Typhoon Fanapi (2010) by its year number, he/she can get all datasets as listed in Table 6 .

To ensure the proper use of the data, the project has its own data sharing policy. All data sources are stored and managed based on the TCLPFieldSED, and shared based on TC Science Data Sharing Platform (http:///0.228.34.9/stid/\#). It was free to access by members of the project team and will be free to the public about 2 years after the completion of the project. The sharing platform has the following advantages, including convenient data acquisition and comprehensive assistant information. There is no need to wait for email notification to obtain data online, and there is no limit on the amount of data downloaded. Users can know not only the necessary information of the spatial-temporal range and resolution, data volume, main parameters, retrieving and downloading data online, but also the general descriptions of relevant data products, such as satellite platforms, observational instruments, projection methods, data processing processes, product inversion algorithms, data quality status, references of some datasets, and so on.

\section{HIGHLIGHTS OF PRELIMINARY RE- SEARCH FINDINGS FROM FIELD CAM-} PAIGNS. The boundary layer structure of landfalling $T C$. The understanding of the structure and physical processes in the boundary layer and the accurate representation of the associated turbulent mixing processes in numerical models are key to improving forecasts of TC track, intensity, and structure changes (Zhang et al. 2015; J. A. Zhang et al. 2017). The data collected from the observational platforms in the coastal area of East China were used to investigate the mean and turbulent boundary layer structure during the landfall of Typhoon Morakot (2009). Results show that the thermodynamic mixed-layer depth and inflow-layer depth are higher during the convective period than the postconvective period. The mixed-layer depth is found to be in the strong inflow layer, but the height of the maximum tangential wind is above the inflow layer, which is contrary to recent observational studies of the boundary layer structure of TCs over open ocean (Zhang et al. 2011). Analysis based on high-frequency wind data shows that momentum flux, turbulent kinetic energy (TKE), and integral length scales of wind speeds 
are all much larger during the convective period than the postconvective period (Fig. 4; Ming et al. 2014), suggesting that convective downdrafts may modulate turbulent flux, TKE, vertical mixing, and the boundary layer recovery processes. The results thus indicate the need to consider convective processes in the boundary layer parameterization.

Based on the high-frequency observational data at the 100-m tower near the coastline of Fujian Province, the fine turbulent structure of the boundary layer was analyzed for landfalling Typhoons Lionrock, Fanappi, and Megi in 2010 (Tang et al. 2015). The results show that during landfall, there are two different scale turbulent energy cascades in the surface layer: one is the forward cascade with turbulence energy transferred from large scale to small scale (downscale cascade), and the other is a reverse cascade with turbulent energy transferred from small scale to large scale (upscale cascade). Further analysis shows that the structure of the upscale cascade occurs in the inner core within 1.5 times the radius of maximum wind, while the downscale cascade is dominant in the outer region outside 1.5 times the radius of maximum wind (Fig. 5). This finding, combined with previous results of Byrne and Zhang (2013), potentially provides a different

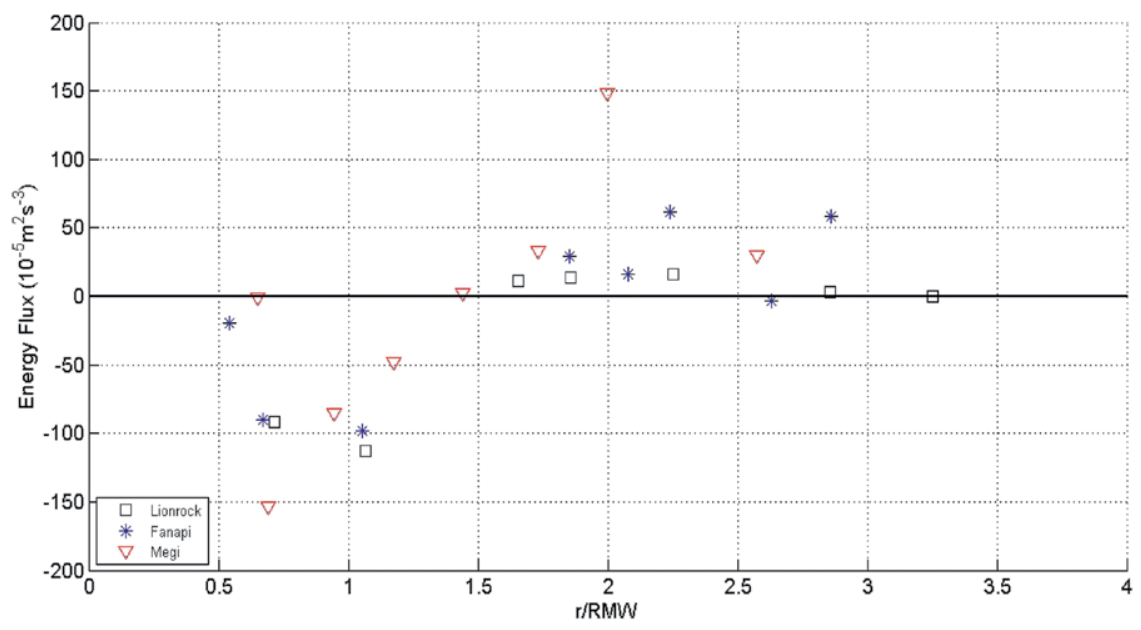

Fig. 5. Plot of the energy flux as a function of the radius normalized by the radius of maximum wind with rectangle for Typhoon Lionrock, star for Typhoon Fanapi, and downward triangle for Typhoon Megi in 2010. (Adopted from Tang et al. 20I5.) perspective from spectral energy flux to understand the turbulent energy scale interaction process that may have not been previously considered in horizontal turbulent mixing parameterizations.

The turbulent mixing in the surface layer determines the exchange of moisture, heat, and momentum between the atmosphere and the underlying surface. The high-frequency wind data collected at the sites of research towers in the surface layer of Typhoons Hagupit (2008) and Chanthu (2010) revealed the characteristics of turbulent parameters under different surface conditions (Ming and Zhang 2018). The turbulent momentum flux, TKE, drag coefficient, and dissipative heating were found to increase with wind speed, and are substantially larger in coastal regions with larger surface roughness than over the open ocean (Bi et al. 2015; Zhao et al. 2015). Dissipative heating estimated based on the parameterized surface friction (Bister and Emanuel 1998) is generally larger than that estimated using the turbulence spectra method from observations. Such an overestimation is much smaller over the coastal land than over the shallow coastal water for a given wind speed. The magnitude of dissipative heating over land is as large as sensible heat flux observed over the ocean, which should not be neglected in numerical models for real-time landfalling TC intensity and structure forecasts. 
Cloud and precipitation microphysical characteristics in landfalling TCs. The ability to accurately predict the magnitude and distribution of latent heat release in TCs is key to TC structure, intensity, and rainfall forecasts by numerical models, but it is quite challenging and remains an elusive goal for the operational and research communities. The latent heat release is closely related to and determined by cloud/precipitation microphysical processes. To document and understand the cloud/precipitation characteristics is important to the improvements of cloud microphysical processes in numerical models. Using measurements from two high-precision $2 \mathrm{D}$ video disdrometers deployed in Jiangsu (East China) and Guangdong (South China) provinces, the characteristics of the drop size distribution (DSD) and drop shape relation (DSR) in seven postlandfalling TCs over China are analyzed (Wen et al. 2018). Although the DSD and DSR are different in individual TCs, the computed DSD parameters in these two provinces possess similar characteristics (Fig. 6). However, the convective precipitation in TC rainbands in continental China contains higher concentration of small raindrops compared to Atlantic TCs (Tokay et al. 2008) and TCs in similar climate regimes, such as in Taiwan (Chang et al. 2009). Moreover, the DSR is found to be more rounded than that in Taiwan area when the diameter is greater than $1.5 \mathrm{~mm}$. This unique characteristics of DSD may be attributed to the interaction between sufficient water vapor brought by a typhoon from the ocean and local anthropogenic aerosol in continental China (Wen et al. 2018). Based on the investigated DSD and DSR characteristics, the new $Z-R$ relation, drop shape relation, and $\mu-\Lambda$ relation for the unique TC microphysics in continental China are obtained, which would be certainly useful for improving the accuracy of quantitative precipitation estimation and model microphysical parameterization for landfalling TCs over mainland China.

With the understanding of DSD from surface disdrometer data, polarimetric radar observations are employed to reveal the kinematic and microphysical structure of inner and outer rainbands in Typhoons Matmo (2014) and Nida (2016) and the corresponding dominant microphysical processes in producing heavy rainfall (M. Wang et al. 2016; Wang et al. 2018; Wu et al. 2018). Results show that the kinematic structure of convective cells in inner rainbands is similar to that of the principal rainband over the ocean (Houze 2010). The hydrometeors within convective regions above the freezing level 

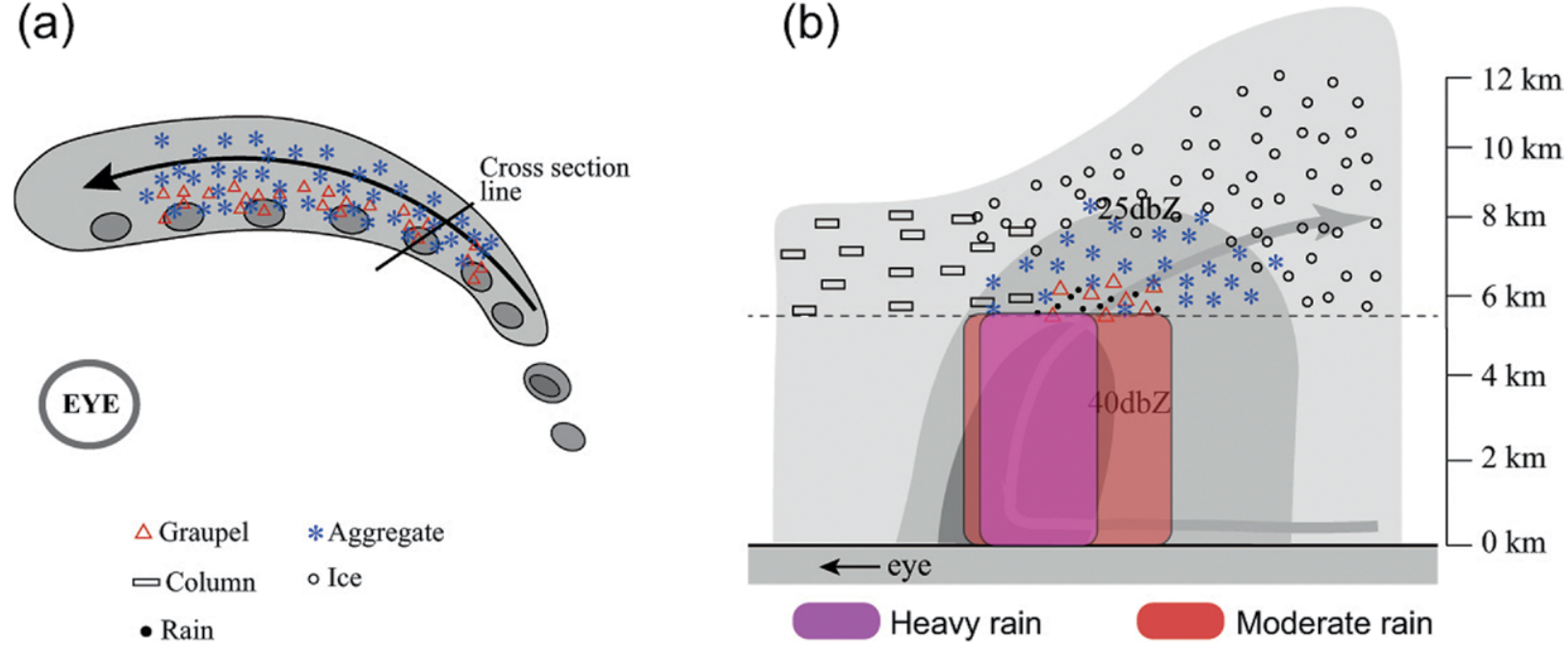

FIG. 7. Schematic showing the location of different types of hydrometeors relative to the kinematic structure in (a) horizontal and (b) vertical directions of the inner rainband of Typhoon Matmo (20I4). The gray arrow in (b) indicates the overturning updraft. The gray dashed line represents the freezing level. (Adopted from Wang et al. 2018.)

present a layered structure, with ice crystals at the top, dry snow in the middle, and graupel at the bottom just above the freezing level. Dry snow and graupel particles are mainly distributed downwind following the overturning updraft. Heavy rainfall occurs mostly in the updraft region predominantly produced through warm-rain processes and the region with graupel produced through melting of graupel particles (Fig. 7; Wang et al. 2018). A new finding is that the autoconversion process mostly occurs below $4 \mathrm{~km}$, which results in small raindrops and may explain the extremely high number concentration of small raindrops in inner rainbands. These results demonstrate the importance of interactions between kinematic and microphysical processes and the evolution of warm-rain processes in inner rainbands of landfalling typhoons.

Different from convection in inner rainbands, which often shows convectively coupled vortex Rossby wave structure (e.g., Li and Wang 2012), convection in outer rainbands observed in Typhoon Nida (2016) exhibits a squall-like structure (Fig. 8; Wu et al. 2018). The microphysics revealed from polarimetric radar in the outer rainband shown in Fig. 8 is quite different from that of the inner rainband analyzed by $\mathrm{M}$. Wang et al. (2016). Whereas M. Wang et al. (2016) found the dominance of warm-rain processes in the inner rainband, particle growth in the outer rainband is dominated by ice-phase cloud microphysical processes. In addition, active riming in outer rainbands is similar to that found in a subtropical squall line (J. Wen et al. 2017).
Severe weather caused by landfalling typhoons. In addition to damages caused by strong winds and heavy rain in the inner core region, TCs can also produce severe weather systems outside the inner core, for example, squall lines, miniature supercells, and sometimes tornados. On 4 October 2015, a tornado of at least EF3 on the enhanced Fujita scale was produced within a miniature supercell embedded in an outer rainband of Typhoon Mujigae in Guangdong Province (South China). Using the observations from the coastal Doppler radars, the structure and evolution of the tornadic miniature supercell was analyzed. This tornadic miniature supercell was found to be similar to those in landfalling hurricanes in the United States. The long-existing miniature supercell was characterized by a hook echo, low-level low notches, an echo top below $10 \mathrm{~km}$, and a small and shallow mesocyclone. As revealed by the dual-Doppler wind analysis, the mesocyclone, which formed an hour prior to tornadogenesis, intensified by the tilting of low-level horizontal vorticity to vertical vorticity and subsequent stretching by strong updraft (Fig. 9). After the mesocyclone reached its peak radar-indicated intensity of $30 \mathrm{~m} \mathrm{~s}^{-1}$, a tornado vortex signature was found between 1 and $3 \mathrm{~km}$ heights above the ground, indicating the existence of a tornado (Zhao et al. 2017).

NEW TECHNICAL DEVELOPMENTS AND APPLICATIONS. The developments of data assimilation systems and improvements of high-resolution numerical models are key to achieving more accurate 

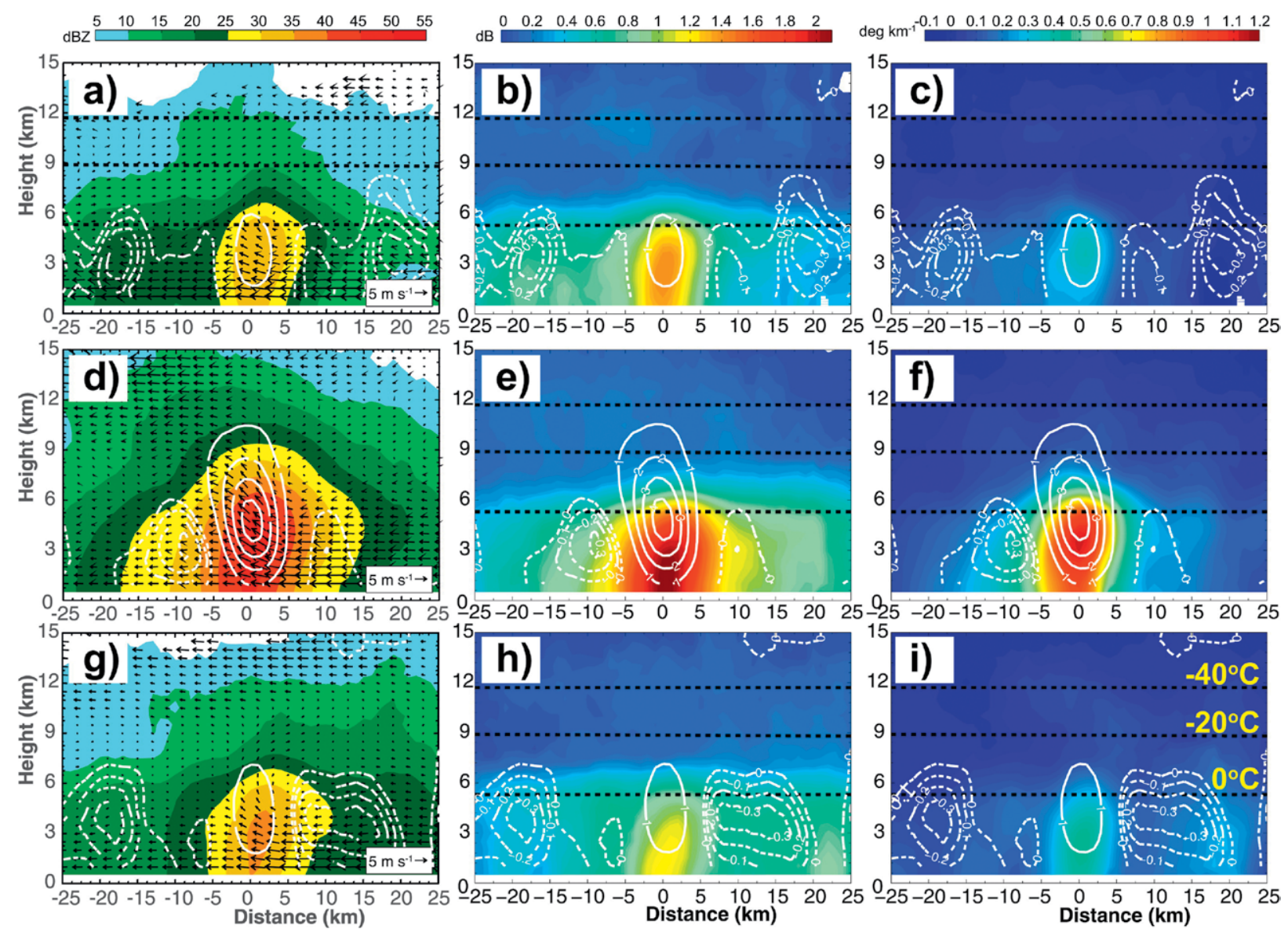

Fig. 8. Composite-mean vertical cross sections of (left) radar reflectivity $\left(Z_{H}\right)$, (center) differential reflectivity $\left(Z_{D R}\right)$, and (right) specific differential phase $\left(K_{D P}\right)$ of the convective cells for (top) developing, (middle) mature, and (bottom) decaying stages along the motion direction of the outer rainband observed in Typhoon Nida (2016). The white contours represent vertical velocity, with solid lines at I $\mathrm{m} \mathrm{s}^{-1}$ intervals for updrafts and dashed lines at $0.1 \mathrm{~m} \mathrm{~s}^{-1}$ intervals for downdrafts. Horizontal dashed black lines indicate altitudes corresponding to $-40^{\circ}$, $-20^{\circ}$, and $0^{\circ} \mathrm{C}$ from top down based on nearby sounding data. (Adopted from Wu et al. 2018.)

forecasts of TC track, intensity, structure, and the associated severe weather. Therefore, as one of the major components of the project, several new technical developments have been achieved, including a multiple ensemble-based data assimilation and application system, a new dual-linear polarization radar data assimilation technique, a rapid cycling radar data assimilation and nowcasting system, a typhoon regional assimilation and prediction system (T-RAPS), and new methods to assess impacts induced by landfalling TCs in China. These developments provide more powerful supports not only to operational TC forecasts but also to research on landfalling TC and will substantially enhance the ability of operational TC forecasts, leading to improved forecast skills for landfalling TCs.

Multiscale ensemble-based data assimilation and application system. A multiscale ensemble-based data assimilation and application system has been developed, which is suitable for both the Advanced Research version of the Weather Research and Forecasting (WRF) Model (WRF_ARW, version 3.8.1) developed by the National Center for Atmospheric Research and the regional version of the Global and Regional Analysis and Prediction System (GRAPES_Meso) developed by CMA. The system assimilates observations in batches on multigrids according to the scales of motion, making the rational use of the multiscale characteristics of observational information. It has the advantage of using multistep data assimilation and a more complete theoretical basis. The system optimizes ensemble members by probability to overcome the influence of bad samples on both background error covariance and mean value. Therefore, it describes more reasonably the characteristics of "flow-dependent propagation" of the observed information than a single-scale assimilation system. Computing the evolution of background error covariance on relatively 

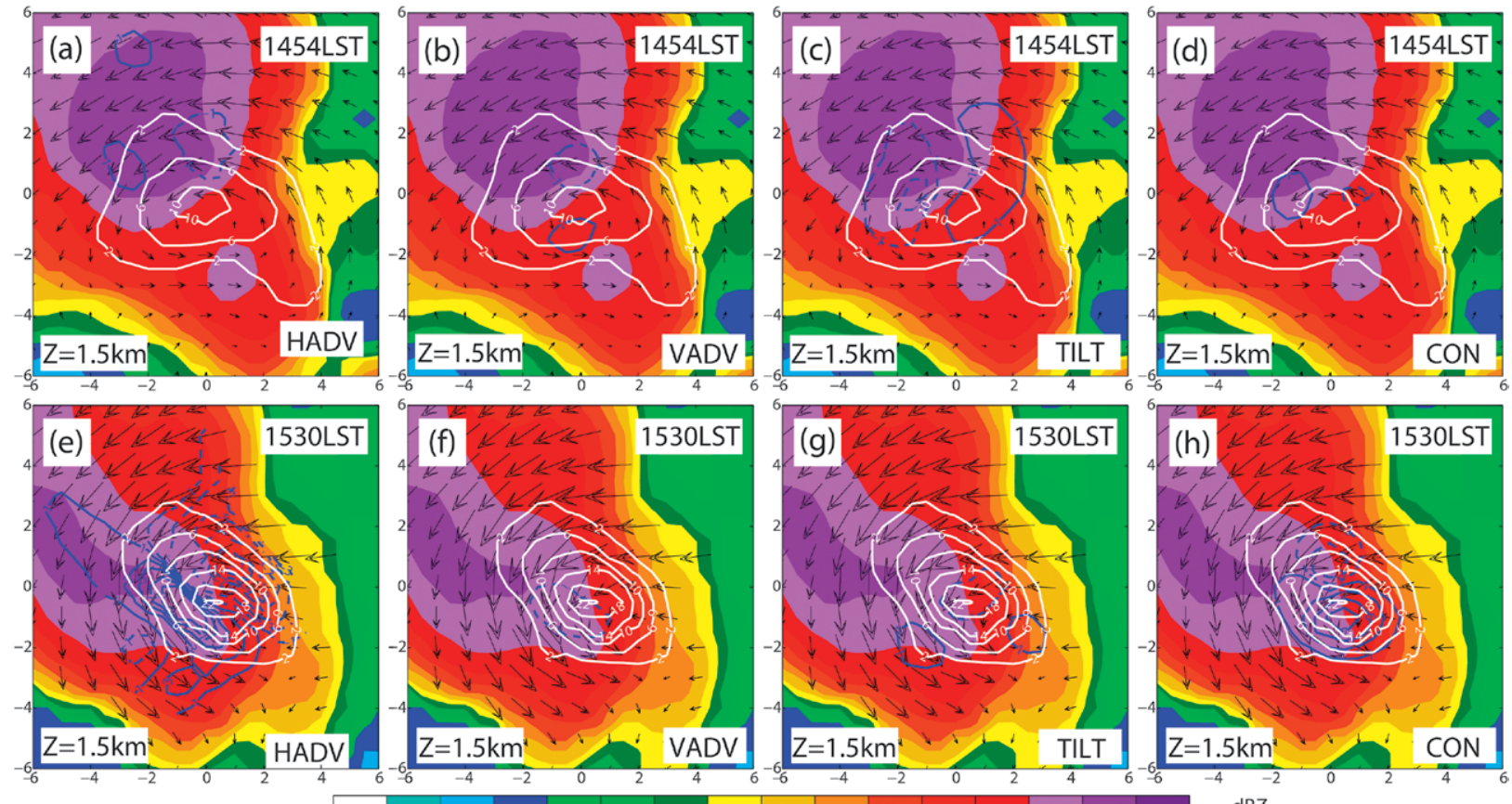

\begin{tabular}{llllllllllllllllll}
\hline 10 & 13 & 16 & 19 & 22 & 25 & 28 & 31 & 34 & 37 & 40 & 43 & 46 & 49 & 52 & 55 & 58 & $d B Z$
\end{tabular}

FIG. 9. Distributions of (a),(e) HADV; (b),(f) VADV; (c),(g) TILT; and (d),(h) CONV terms within the mesocyclone at $1.5 \mathrm{~km}$ at (top) 1454 and (bottom) 1530 LST, corresponding to the times before and near tornadogenesis. Blue solid (dashed) contours denote positive (negative) contributions to vertical vorticity production with the interval of $2 \times 10^{-6} \mathrm{~s}^{-2}$. Reflectivity (dBZ, color shading) is overlaid with the storm-relative wind vectors and vertical relative vorticity (white contours with intervals of $4 \times 10^{-3} \mathrm{~s}^{-1}$ ). (Adopted from Zhao et al. 20I7.)

large grids helps to overcome "small-scale pollution" and reduce computational costs. Similar to Xie et al. (2011), the system realizes hybrid assimilation of multiscale fields and overcomes the insufficiency of regional data assimilation in updating the large-scale circulation. Moreover, the results from this system are closer to observations, which is different from the ensemble Kalman filter (EnKF; Houtekamer and Zhang 2016), which is closer to perturbation observations. The simulation of Typhoon Nida (2016) is given as an example of the applications of the developed assimilation system. Typhoon Nida was observed by the aircraft of Hong Kong Observatory at 0900 UTC 1 August 2016. Figure 10 compares the central sea level pressure changes without and with the aircraft observational data assimilated and the corresponding storm center positions of ensemble samples. Both the central sea level pressure and the average position in the analysis with aircraft data assimilation are closer to those observed than those without aircraft data assimilation (Figs. 10a,b). The storm structure is also much improved with the aircraft data assimilated (Fig. 10c).

Based on this system, the effect of sample optimization on data assimilation and forecast has been evaluated. Ensemble forecasting is widely applied to numerical weather prediction. However, the ensemble does not meet a perfect Gaussian probability distribution because of limited ensemble members used. Some members are well away from the true atmospheric state. Such outliers (with low probability) may downgrade the accuracy of an ensemble forecast. This problem is overcome by restricting the probability distribution so that the ensemble spread could be reduced through sample optimization. The method uses the observed TC track to limit the distribution of ensemble samples (Fig. 11). Samples close to the expected values (observations) are identified as good, and those with low probability are regarded as bad and are replaced with good samples to reflect the true state as much as possible (Li et al. 2018). Different from the method proposed by Qi et al. (2014) and Dong and Zhang (2016), who chose good subsets only and, as a result, the number of members in the ensemble varied, in our method the total number of members in the ensemble is fixed by increasing members in the selected good subsets. Specifically, our sample optimization involves the substitution of the deleted bad samples by the new perturbed good samples in the good subsets and updated by assimilating observations. The covariance is thus calculated using good and moderate samples. The prediction 

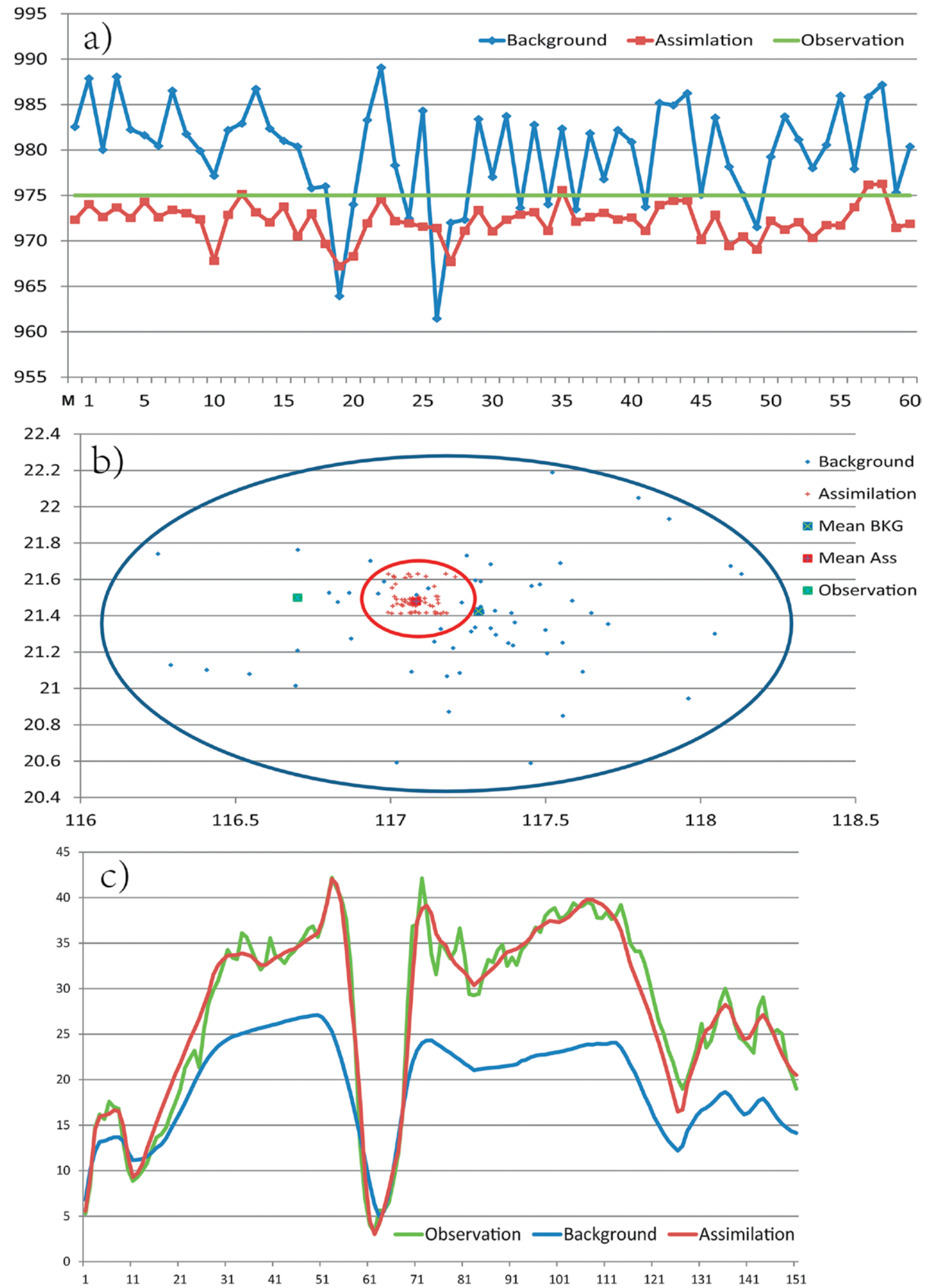

Fig. 10. (a) The sea level pressure (hPa) at the typhoon center in the background field (blue), the analysis field (red), and the typhoon warning information (green), with " $M$ " in the $x$ axis representing ensemble mean, while numbers I-60 show each ensemble member. (b) The location of the typhoon center in the background field (blue), the analysis field (red), and the typhoon warning information (green) in longitude $\left({ }^{\circ} \mathrm{E}\right)$ and latitude $\left({ }^{\circ} \mathrm{N}\right)$. (c) The wind speed $\left(\mathrm{m} \mathrm{s}^{-1}\right)$ observed by aircraft (green), the background field (blue), and the analysis field with aircraft data assimilation (red), with the $x$ axis showing each observation point. 


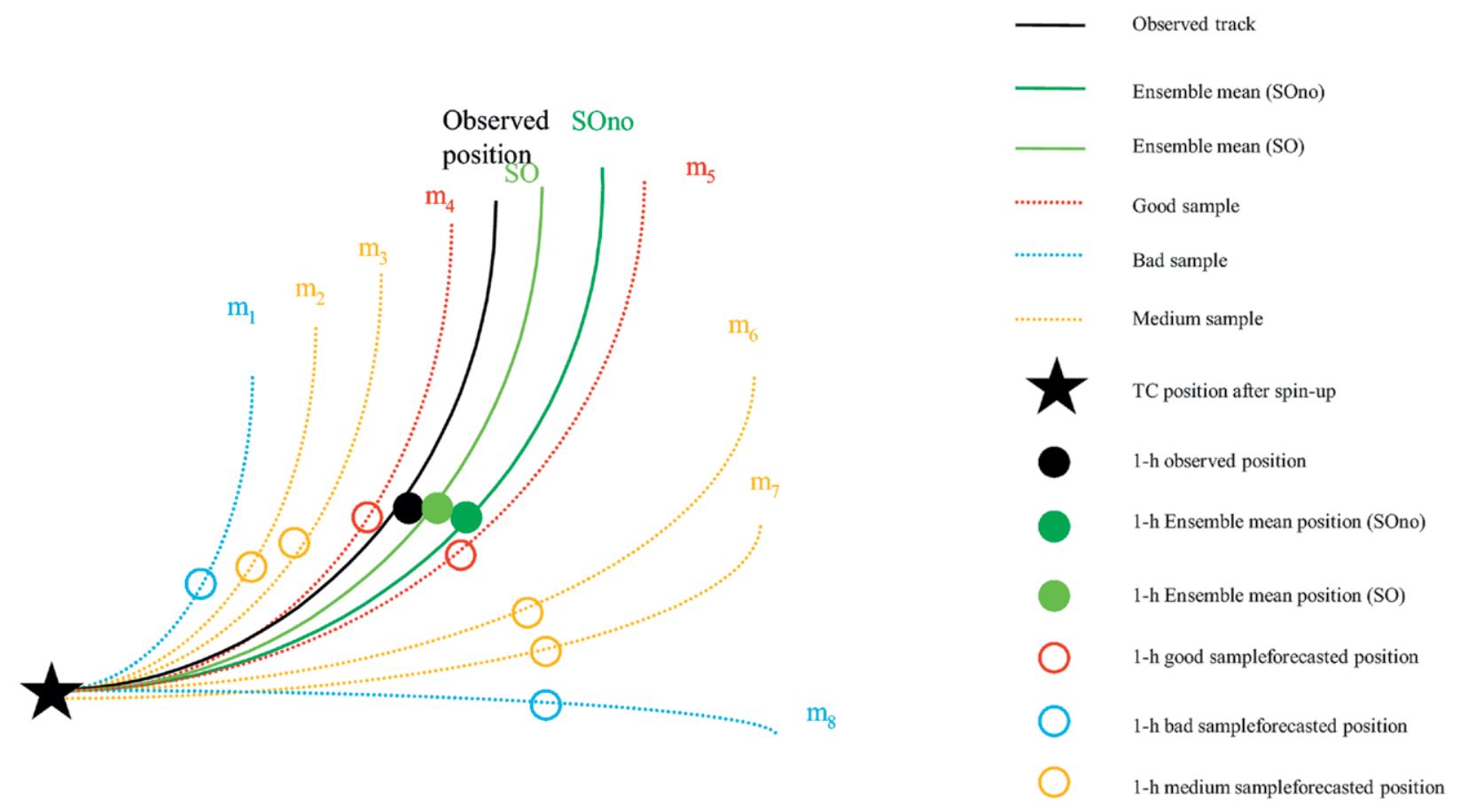

FIG. II. Schematic illustration of the I-h difference between the time when ensemble members arrive and the time when ensemble mean arrives.

results for three targeted TCs in 2016 (Rammasun, Nida, and Megi) show reduced track and intensity errors by the new sample optimization (Fig. 12).

Dual-linear polarimetric radar data assimilation technique. The assimilation technique of radar radial velocity has been relatively mature and widely used in improving forecast of mesoscale convective systems. Recent efforts have been devoted to assimilating hydrometeors from polarimetric radar observations. Variables from polarimetric radar observations cannot be directly used as model variables because of the complex nonlinear relationship between polarimetric radar observations and microphysical characteristics of hydrometeors. Therefore, a direct link between polarimetric radar observations and model variables should be developed for data assimilation. Due to discontinuity in both spatial and temporal distributions of hydrometeors, the assimilation of polarimetric radar data involves two issues. The first issue is how to modify the information of hydrometeors in the model initial conditions based on the observational data when both the model initial condition and polarimetric radar data have hydrometeor information. The second issue is how to appropriately add new information of hydrometeors when the polarimetric radar has observed hydrometeor information, but the model initial condition has no such information. To solve the first problem, a forward modeling framework-a polarimetric radar simulator-has been constructed with the model variables as input and polarimetric radar variables as output. To solve the second problem, the retrieval operator of polarimetric radar observations, by which parameters of raindrop spectrum are calculated from polarimetric radar observations, is used to transform polarimetric radar variables into model variables. A simulator for S-band polarimetric radar has been developed based on the Rayleigh-Gans scattering theory (H. Wang et al. 2016). Four hydrometeors (rain, ice, snow, and graupel) have been considered in the simulator. The mixing ratio and number concentration of each hydrometeor, axis ratio, relative dielectric constant, and canting angles of particles are all inputs of the simulator, and reflectivity at horizontal and vertical polarizations, differential reflectivity, specific differential phase, and others are then calculated.

Meanwhile, we updated the raindrop axis ratio relationship ( $r-D$ relation) based on the $2 \mathrm{D}$ video disdrometers observations in South China during the field experiment of the LTCRP. Figure 13 shows the scatterplots and the fitted curve of the observed $r-D$ relationship from our field experiments. The relationship in the United States given by Zhang et al. (2016) and that in North China given by G. Wen et al. (2017) are also shown for a comparison. The $r-D$ relation is obviously different from those in the United States and North China. For a given $D$ 
value between 2 and $5 \mathrm{~mm}$, our fitted $r$ has a larger value, suggesting that for the same size, the shape of raindrops is more rounded in South China than those in the United States and North China. With

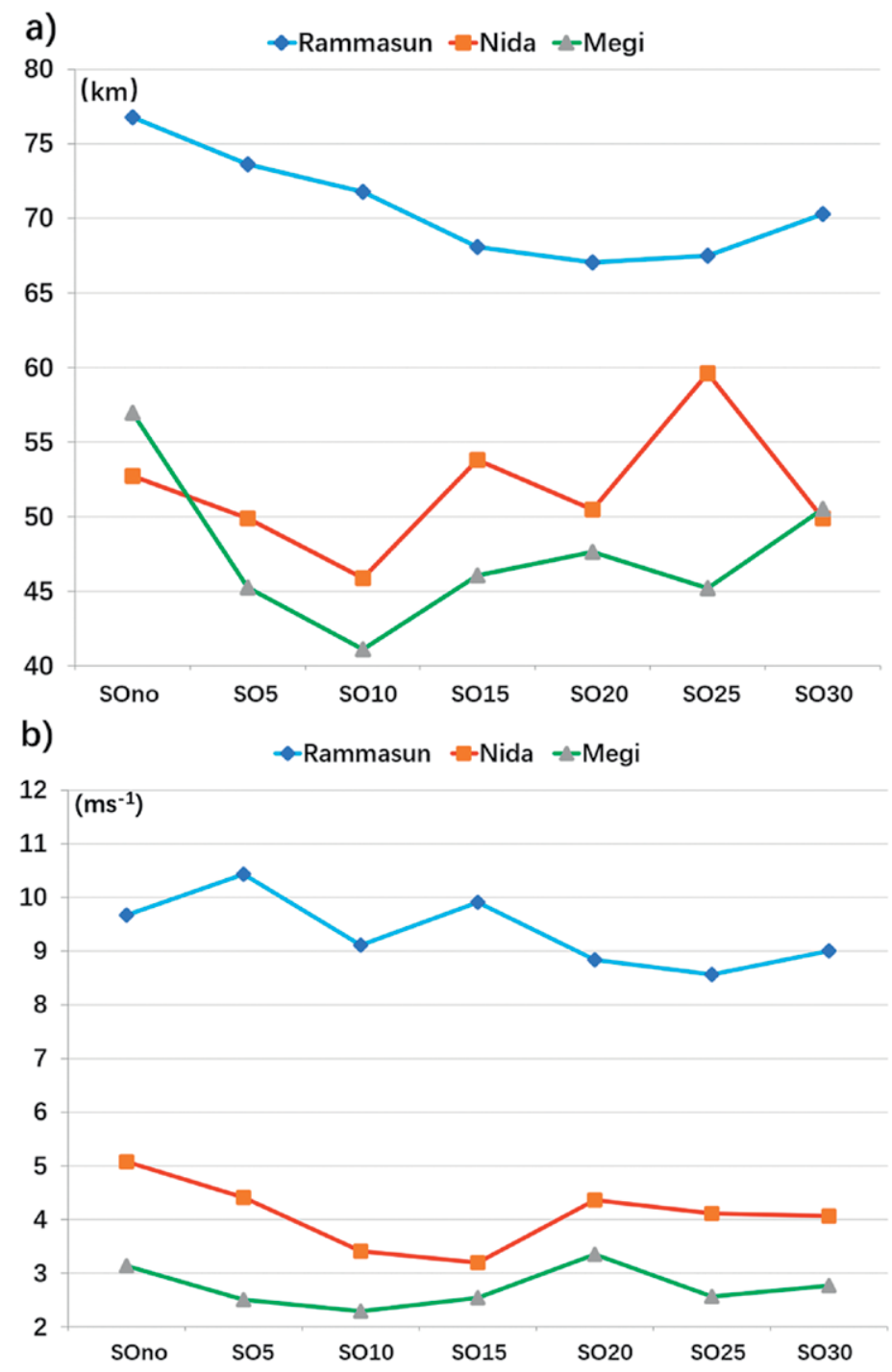

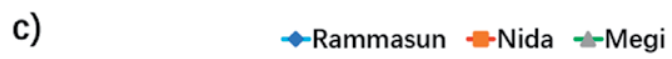

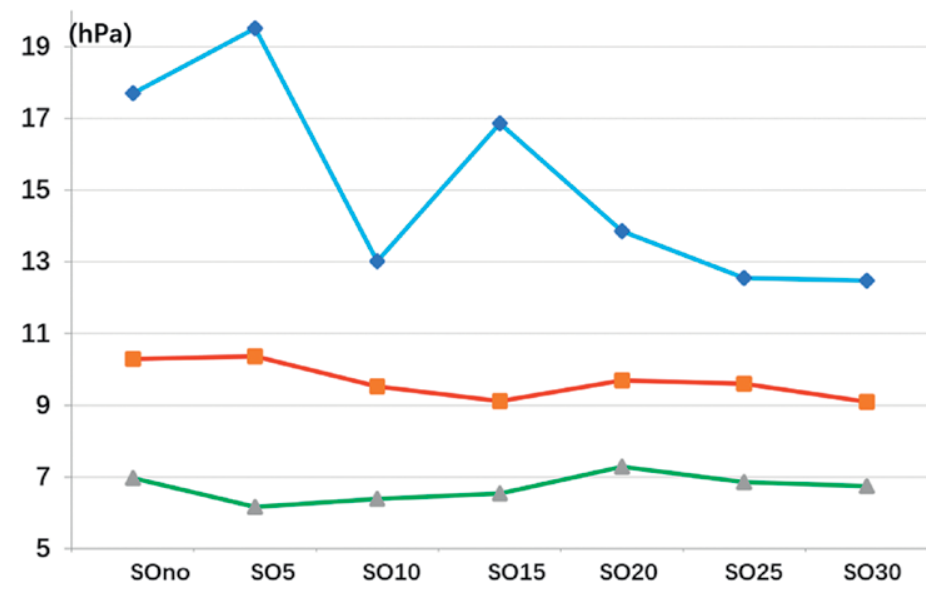

the representative $r-D$ relation in South China, the differential reflectivity and specific differential phase calculated by S-band polarimetric radar simulator are closer to the actual polarimetric radar observations. A direct link between the model variables and polarimetric radar observations can be established by using this simulator and can be used as a tool to evaluate the model predictions and to directly assimilate the polarimetric variables into convection-resolved models. According to the statistical shape-slope $(\mu-\Lambda)$ relationship observed by $2 \mathrm{D}$ video disdrometers for the first time in South China, a constrained gamma model was proposed for the retrieval of rain DSDs from S-band polarimetric radar observations. Based on long-term $2 \mathrm{D}$ video disdrometer observations, the $\mu-\Lambda$ relationship, $\Lambda=0.0241 m^{2}+0.867 \mu$ +2.453 , was obtained for South China. The gamma size distribution parameters can be retrieved from polarimetric radar measurements of radar reflectivity and differential reflectivity by the constrained gamma model of retrieval scheme. Then we can calculate the model variables from the DSD information, and thus apply to data assimilation in convection-resolved numerical models.

Typhoon Hato (2017) is selected as an example to demonstrate the impact of radar data assimilation. The Morrison double-moment microphysical scheme (Morrison et al. 2005), which contains six hydrometeors (cloud, rain, ice crystals, snow, and graupel), is used. Under the condition of certainty about the size

FIG. 12. Mean absolute error between observation and individual ensemble members SOno, SO5, SOI0, SOI5, SO20, SO25, and SO30 in (a) track, (b) central sea level pressure in $\mathrm{hPa}$, and (c) maximum $10-\mathrm{m}$ height wind speed in $\mathrm{m} \mathrm{s}^{-1}$ for Typhoons Rammasun (1800 UTC I7 Jul to I800 UTC I9 Jul 2014), Nida (0900 UTC I Aug to 1800 UTC 2 Aug 2016), and Megi (0900 UTC 26 Sep to 2100 UTC 28 Sep 2016). SOn represents ensemble forecast with sample optimization, in which $\boldsymbol{n}$ bad samples are replaced by $\boldsymbol{n}$ perturbed good samples. For example, SOno means no sample optimization and SO5 means five bad samples being replaced by five perturbed good samples in the sample optimization. (See text for more details.) 
distributions of hydrometeors, radar reflectivity at horizontal polarizations can be acquired from scattering matrix and particle swarm reflectivity of radar observations. The radar data are assimilated in the model at 0600 and 1800 UTC 22 August 2017, and then deterministic forecasts are initiated from the ensemble mean of the EnKF analyses. The results show that the simulated radar echo intensity and location are improved with the radar reflectivity data assimilated, and the distributions of water vapor, hydrometeors, and temperature with radar data assimilation are all closer to observations (Fig. 14). With the radar data assimilated, the predictions of 6 - and 24-h accumulated precipitation amount and location are significantly improved, especially for rainstorm and severe rainstorm, with the threat scores of light rain, moderate rain, and rainstorm improved by about $17 \%, 59 \%$, and $132 \%$, respectively.

Rapid cycling radar data assimilation and TC nowcasting system. With decades of efforts of CMA, the mean distance between two neighboring Doppler weather radars is about $180 \mathrm{~km}$ along the coast of mainland China. Coastal radar can observe fine structure of the TC inner core $4-6 \mathrm{~h}$ prior to the landfall of a TC. These radar data are of great value for quantitative precipitation estimate and forecast of landfalling TCs. At present, due to the difficulty in quality control of radar data, lack of ability to assimilate such high spatial and temporal resolution observations, and lower computing capacity, the ground-based radar data in China have not been assimilated into operational TC forecasting models yet. As part of this project, a rapid cycling radar velocity data assimilation and TC nowcasting system has been developed based on EnKF.

The numerical model used in this system is the WRF-ARW Model version 3.8.1. The initial and lateral boundary conditions are provided by the final analyses of the National Centers for Environmental Prediction's (NCEP) Global Forecast System (GFS). The model is set to 43 vertical levels with the model top at $50 \mathrm{hPa}$. Three two-way-nested domains are used with their respective sizes of $120 \times 100,151 \times$ 151 , and $169 \times 169$ grid points and corresponding grid spacings of $40.5,13.5$, and $4.5 \mathrm{~km}$ for D01, D02, and D03, respectively. The system includes independently developed data quality control (Xiao et al. 2016), preprocessing module for S-band Doppler radar, the initial ensemble perturbation module combining WRF 3DVar package (Barker et al. 2004) with "cv3" background error covariance option, cycling data assimilation module, ensemble forecasting module,

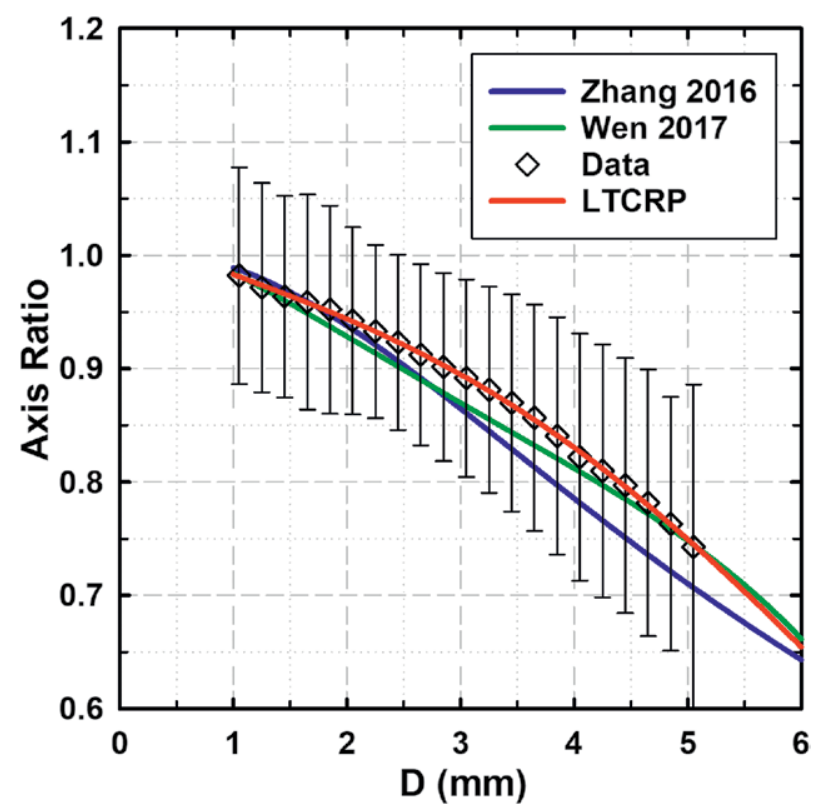

FIG. I3. The $r-D$ relation (diamonds) and fitted curve (red) observed by 2D video disdrometers during the field campaign of LTCRP. The $r-D$ relation in the Unites States from Zhang et al. (2016) and that in North China from Wen et al. (2017b) are provided for a comparison.

and deterministic forecasting module. With continuous performance tuning, parameters (such as ensemble spread, time interval of cycling data assimilation, inflation method and its coefficient, and horizontal and vertical localization radius) suitable for radar observations of landfalling TCs over China are determined. A new "space-evenly" radar data thinning method has also been developed in the data preprocessing module, which can keep almost equal data density everywhere in one scanning volume without apparent harm to the quality of thinned radar data. Compared with the mainstream radial space thinning algorithm (F. Zhang et al. 2009; Zhu et al. 2016), more observations near the TC center are used, which can further correct the TC location and intensity in the model. In total, 60 ensemble members are used to estimate the background error covariance with the flow-dependent characteristics in the data assimilation system. Radar radial velocity data are cyclically assimilated four times with a 1-h interval for $4-8 \mathrm{~h}$ prior to a TC making landfall. After cycling radar data assimilation, the deterministic forecast is initialized with the mean of the updated members.

Typhoon Mujigae (2015) is taken as an example to demonstrate the ability of the developed nowcasting system in predicting precipitation. Mujigae made landfall near Zhanjiang in Guangdong Province around 0400 UTC 3 October 2015 after its rapid intensification 

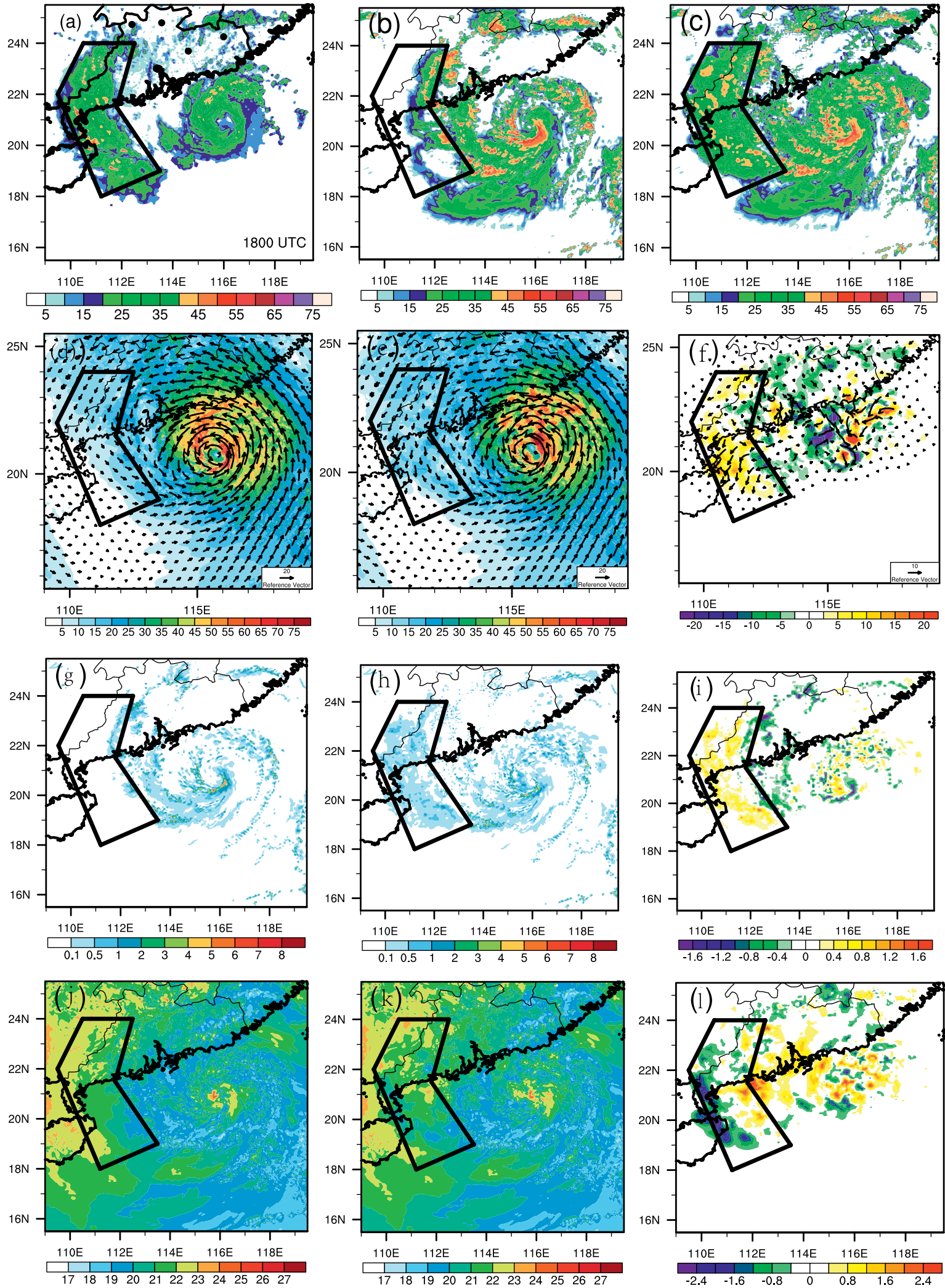

FIG. 14. Composite radar reflectivity (dBZ) for (a) observation with dark spots indicating radar locations, (b) before assimilation, and (c) after assimilation, and (d)-(f) fields of water vapor flux $\left(\mathrm{g} \mathrm{kg}^{-1} \mathrm{~m}^{-2}\right),(\mathrm{g})-(\mathrm{i})$ rainwater mixing ratio $\left(\mathrm{g} \mathrm{kg}^{-1}\right)$, and $(\mathrm{j})-(\mathrm{I})$ temperature $\left({ }^{\circ} \mathrm{C}\right)$. (from left to right) Before assimilation, after assimilation, and the corresponding increments at 1800 UTC 22 Aug. Note that the outlined area indicates the convective rainbands to the west of the storm center in observations as shown in (a). 

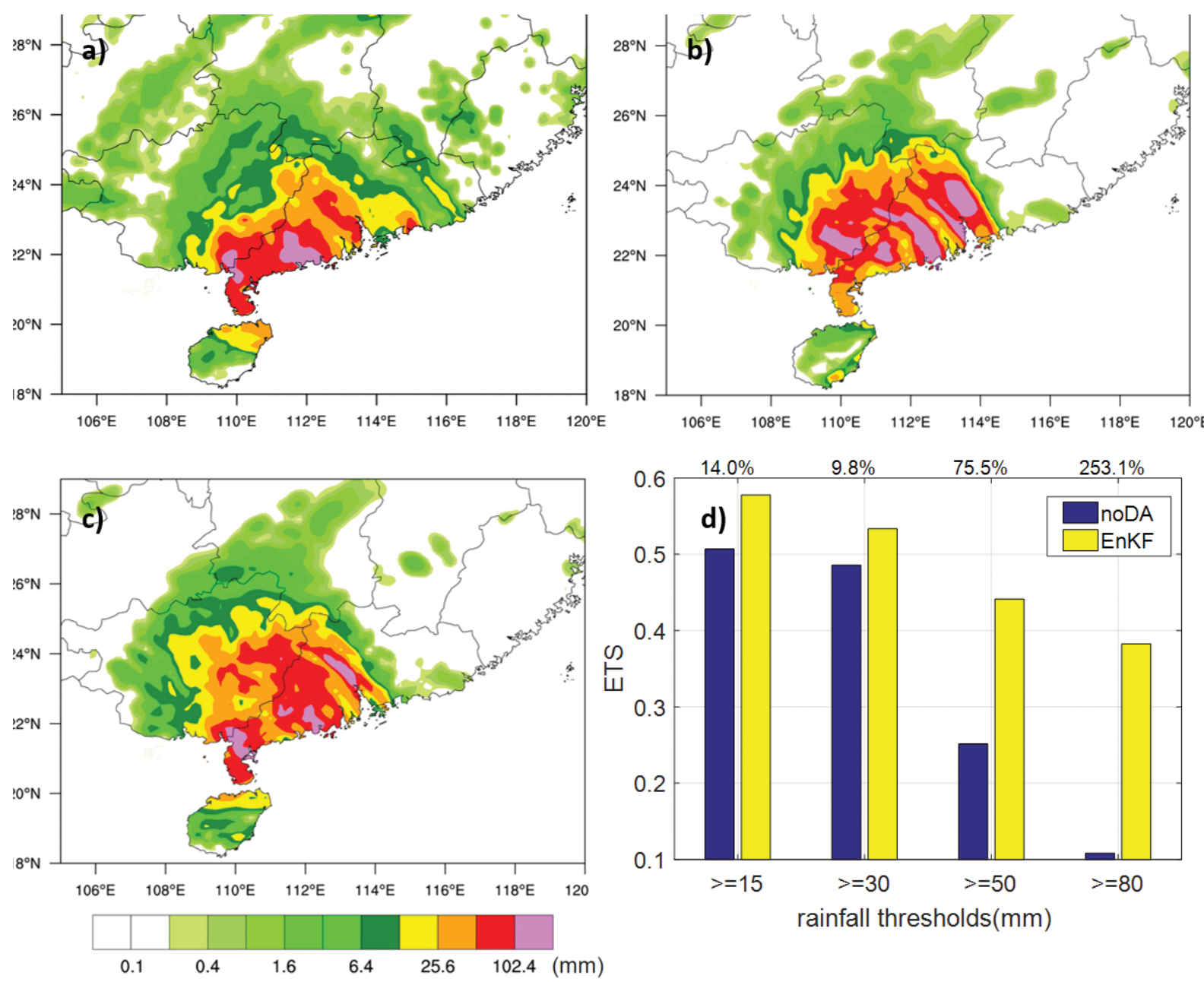

FIG. I5. Nine hours of accumulated precipitation $(\mathrm{mm})$ of Typhoon Mujigae after its landing (0400-I200 UTC 3 Oct 20I5). (a) Observation from rain gauge, (b) forecast experiment without data assimilation, (c) forecast experiment after four times cycling data assimilation, and (d) the equitable threat scores (ETS) of 9-h accumulated precipitation for the corresponding experiments. The number at the top above each bar in (d) represents the EnKF increment percentage relative to noDA.

offshore. At landfall, the maximum surface wind speed was up to $59 \mathrm{~m} \mathrm{~s}^{-1}$ and central sea level pressure was $937 \mathrm{hPa}$ according to the best track data of the Joint Typhoon Warning Center (JTWC). Mujigae caused severe flooding and direct economic loss of more than RMB 25 billion. There were 7.479 million people affected by Mujigae, including 19 fatalities. The Doppler radar at Haikou observed the rapid intensification of Mujigae. Four cycles of radar data assimilation were performed from 0000 UTC 4 October prior to the deterministic forecast initialized at 0300 UTC 4 October. The results show that the extreme rainfall north of the Pearl River estuary was reduced and precipitation over the Leizhou Peninsula and Hainan Island increased with data assimilation and are closer to the observed rainfall distribution (Fig. 15). In addition, the forecasted extreme rainfall area with no data assimilation was much larger than that in observation. This false alarm is somehow corrected by radar data assimilation. A quantitative evaluation indicates that the radar data assimilation improves skill for moderate rainfall

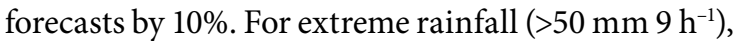
which is the main cause of damage, the equitable threat score (ETS) increased drastically with radar data assimilated (Fig. 15d), suggesting that the nowcasting system has potential skill in precipitation forecasts for landfalling TCs.

Typhoon Regional Assimilation and Prediction System. The Typhoon Regional Assimilation and Prediction System (T-RAPS) is a quasi-operational typhoon forecasting system for the western North Pacific (including the South China Sea) developed at the State Key Laboratory of Severe Weather (LaSW) in CAMS/ CMA. The system can be run in real time or in the hindcast mode for historical TCs. The WRF-ARW 
Model is used in the system but with modifications and implementations of several key physics packages. The new vortex dynamical initialization scheme is developed to improve the TC structure, intensity, and location, especially under the influence of terrain, in model initial conditions, and to achieve a warm model startup (Cha and Wang 2013; Liu et al. 2018). Several new physics packages are used in the latest version of T-RAPS, including the CAMS cloud microphysical parameterization scheme (Gao et al. 2011, 2016), the $E-\varepsilon$ boundary layer parameterization scheme (Wang 1999, 2001), the new modified Tiedtke cumulus parameterization scheme (Zhang and Wang 2017), the delta-four-stream discrete ordinates adding method for radiative flux calculations (delta-4DDA scheme; F. Zhang et al. 2013, 2016, 2017, 2018). The T-RAPS also includes its own post-processing module (5 types of 32 products are generated in real time), its product web page and a verification module. The system is run automatically from input data downloading from the global analysis and forecast of NCEP GFS, model preprocessing and integration, and model output postprocessing to product uploading for website display and forecast verification (Fig. 16).

The T-RAPS has been running quasi operationally in real time since 2014 on the CMA IBM high-performance computing (HPC) server during typhoon season. The basic model configuration in

the quasi-operational real-time forecasting version of the T-RAPS is shown in Table 7, which has three two-way nested domains with the finest horizontal resolution of $2 \mathrm{~km}$ in the innermost domain. The model atmosphere has 50 vertical levels with the model top at $10 \mathrm{hPa}$. The performance of T-RAPS in predicting TC track and intensity forecast since 2014 is shown in Fig. 17. Both track and intensity errors are larger in 2014 when the T-RAPS was initially set up but then show a continuous reduction year by year. The model performance in the past 5 years is also compared with two other regional TC models for the western North Pacific (Fig. 18), namely, the HWRF of NCEP (Tallapragada et al. 2015) and the ACCESS-TC of the Australian Bureau of Meteorology (Davidson et al. 2014). For the track forecast, the average 24, 48, and $72 \mathrm{~h}$ forecast errors of HWRF, T-RAPS, and ACCESS-TC are 146, 128, and $186 \mathrm{~km}$, respectively, during the 2014-18 seasons. The T-RAPS shows the best performance, followed by HWRF and

\begin{tabular}{|c|c|c|c|}
\hline Forecast lead time & \multicolumn{3}{|c|}{$72 \mathrm{~h}$} \\
\hline Resolution (km) & 18 & 6 & 2 \\
\hline Grid domain & $311 \times 251$ & $27|\times 27|$ & $211 \times 211$ \\
\hline Moving nest & No & \multicolumn{2}{|c|}{ Yes } \\
\hline Vertical level & \multicolumn{3}{|c|}{50} \\
\hline Model top (hPa) & \multicolumn{3}{|c|}{10} \\
\hline Time step (s) & 60 & 20 & 6 \\
\hline Cumulus parameterization scheme & $\mathrm{KF}($ new Eta) & \multicolumn{2}{|c|}{ No } \\
\hline Microphysical parameterization scheme & \multicolumn{3}{|c|}{ WSM6 } \\
\hline PBL parameterization scheme & \multicolumn{3}{|c|}{ YSU } \\
\hline Surface layer parameterization scheme & \multicolumn{3}{|c|}{ Revised MM5 M-O } \\
\hline Radiation scheme & \multicolumn{3}{|c|}{ RRTMG/RRTMG } \\
\hline Land surface scheme & \multicolumn{3}{|c|}{ Unified Noah land surface } \\
\hline
\end{tabular}

ACCESS-TC. For the intensity forecast, the averaged 24, 48, and $72 \mathrm{~h}$ forecast errors of HWRF, T-RAPS, and ACCESS-TC are 7.8, 8.4 , and $8.8 \mathrm{~m} \mathrm{~s}^{-1}$, respectively. T-RAPS ranks in the middle, but the differences among the three models are small. Although all the three models show a general improvement in the past 5 years, the T-RAPS shows a more pronounced improvement in the most recent 3 years. Note that part of the newly implemented 
physics packages improve the overall performance of the T-RAPS, but those have not been included in Figs. 17 and 18.

The real-time forecast products of T-RAPS have been provided to several official typhoon forecasting units in China, including the National Weather Consultation, the National Typhoon Emergency Response Service, and some other administrative professional forecasting services, such as the electric power sector, Chinese Ocean Agency, and Zhuhai Meteorological Bureau. In addition, the T-RAPS has also been used as a research platform for researchers to conduct real-case or idealized simulations to understand TC dynamics and physical mechanisms (e.g., X.-H. Zhang et al. 2017; Wang et al. 2019) and as a test bed to evaluate new model developments. In addition, an atmosphere-ocean coupled version of T-RAPS is under development and is planned to be run in real time from 2020 , namely, by the end of the 10 -yr project. a)

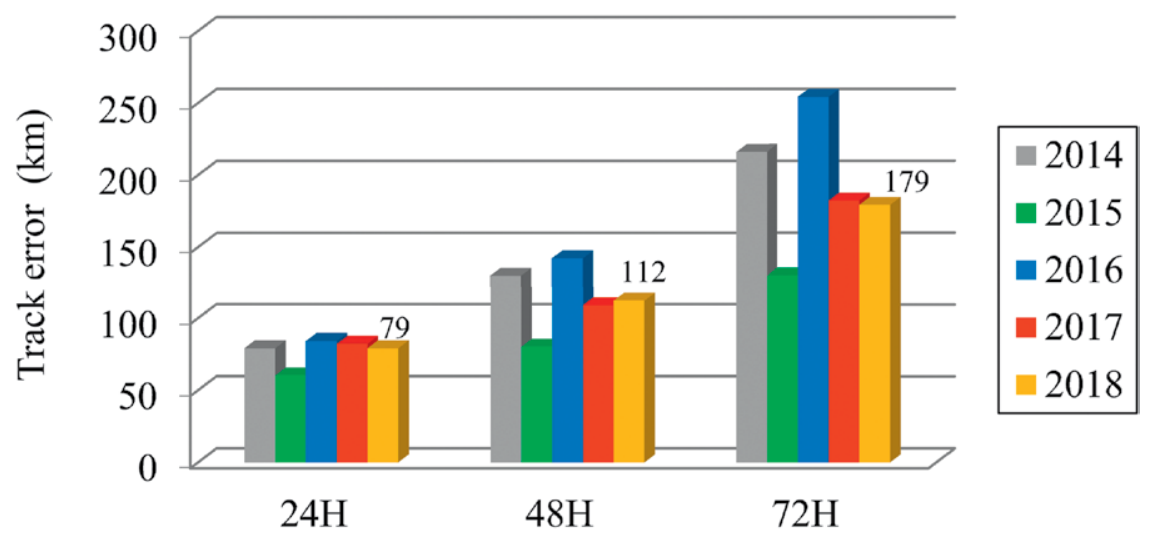

Forecast lead time

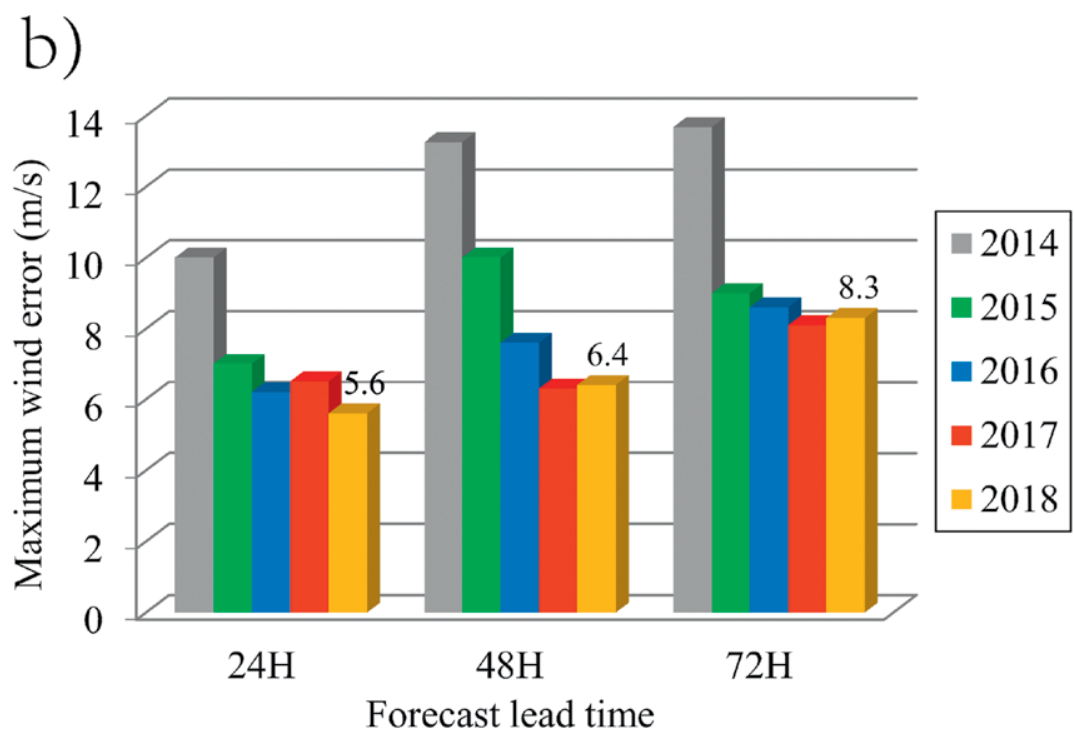

FIG. I7. Averaged track and intensity errors of real-time forecasts by the T-RAPS during 2014- I8.
Methods to assess impacts induced by landfalling TCs. A last part of the project is to develop methods to assess impacts induced by landfalling TCs. In China, the rainstorm induced by landfalling TCs is one of the most severe meteorological disasters. TCs with only rainstorm is more than $65 \%$ in all cases at stations. To assess the destructive power of rainstorm caused by landfalling TCs in a province, an integrated Disaster-Causing Rainstorm Severity Index (DRaSI) for a specific rainstorm event has been developed based on the DRaSI model for a single station (Chen et al. 2019). The DRaSI model for a single station is estimated by the ratios of the total precipitation, the maximum daily precipitation, and the rainstorm days to their corresponding climatological background states.
The relationships between TC precipitation, wind, and storm damage are analyzed for mainland China based on 424 TCs from 1984 to 2013 to construct a destructive potential index. The analysis shows that the maximum daily areal precipitation (MDAP) from stations with daily precipitation of $\geq 50 \mathrm{~mm}$ and the sum of wind speeds of $\geq 13.9 \mathrm{~m} \mathrm{~s}^{-1}$ (GUST7_T) can be used to estimate the damage caused by landfalling TCs. An index combining the precipitation and winds of a TC (IPWT) is defined to estimate the severity of the combined impact of precipitation and wind caused by TCs based on the dimensionless parameters of MDAP and GUST7_T. The correlation coefficient between damage and IPWT is 0.80 for 424 TC cases. All TCs over mainland China are divided into five 
categories, consistent with the damage categories (P.-Y. Chen et al. 2013), based on IPWT, where higher categories refer to higher impact and higher potential damage caused by TCs. The IPWT and its classification can be used to simply assess the impact and the potential damage caused by landfalling TCs accurately. Further analysis of the annual frequency of the combined precipitation-wind impact categories reveals no significant increasing or decreasing trend in the impact by landfalling TCs over mainland China in the past 30 years (Chen et al. 2019).

The vulnerability of population and economic factors are important for estimating disaster losses. The social vulnerability index (SoVI) reflecting the ability to confront TCs is introduced to assess the vulnerability of population (P.-Y. Chen et al. 2013; Lu et al. 2018). A comprehensive risk index for TCs is constructed and used to zone areas of risk based on an intensity index of disaster-causing factors, and a population vulnerability index are developed for Zhejiang Province, East China. It is shown that the southeastern Zhejiang, especially in the border region between Taizhou and Wenzhou cities, is the area mostly affected by TC disasters during 1980-2014 because of the most vulnerable population with the relatively undeveloped economy, mountainous terrain and the high risk of geological disasters in the region. Vulnerability is lower in cities due to better disaster prevention, reduction strategies, well-educated population (Lu et al. 2018).

SUMMARY AND CONCLUDING REMARKS. This article has provided an overview on the national LTCRP in China, a 10-yr (2009-19) project jointly supported by China Ministry of Science and Technology, CMA, Ministry of Education, and Chinese Academy of Sciences. The LTCRP includes three main components: field experiment, scientific research, and technical developments. The field experiment with field campaigns is to obtain in situ and remote sensing data of landfalling TCs over mainland China, with the focus on observations of the fine structure of the boundary layer and cloud microphysics in landfalling TCs. The data collected are used for both scientific research and improvements and verification of numerical models used for prediction of landfalling TCs. Scientific research focuses on improving both the boundary layer and cloud microphysical processes in landfalling TCs. Technical developments focus on new data assimilation algorithms for effective use of various observational data, a rapid cycling radar data assimilation and nowcasting system, a numerical TC forecasting system, and methods to assess impacts of landfalling TCs in mainland China.

We have introduced the main observing system developed under this project, including instruments 
and equipment, design and implementation of the TC field campaigns, and the data management and data sharing policy. During the 11-yr period 2008-18 (including the pre-project year 2008), the field experiment targeted 24 landfalling TCs and collected the first-hand observational data (Table 5). Based on these data, some boundary layer and cloud microphysical processes in landfalling TCs have been analyzed and investigated with several primary new findings, as summarized in the section "Highlights of preliminary research findings from field campaigns."

Results from an analysis based on high-frequency wind data show that momentum flux, TKE, and integral length scales of wind speeds in the boundary layer of landfilling TCs are all much larger during the convective period than the postconvective period, suggesting potential modulation of turbulent flux, TKE, vertical mixing, and boundary layer recovery by convective downdrafts and indicating the need to consider convective processes in the boundary layer parameterization. Two different scale turbulent energy cascades, namely, the inner-core upscale cascade and the outer-core downscale cascade, are found in landfalling TCs. This finding potentially provides a different perspective to understand the turbulent energy scale interaction process that has not been previously considered in horizontal turbulent mixing parameterizations. Results also show that the surface layer drag coefficient and dissipative heating are substantially larger in coastal regions than over the open ocean, and dissipative heating over land is as large as sensible heat flux over the ocean and thus should be considered in numerical models for real-time forecasts of landfalling TCs. Measurements from high-precision 2D video disdrometers are used to reveal the characteristics of the DSD and DSR in seven postlandfalling TCs over China. Based on these characteristics, the new $Z-R$ relation, drop shape relation, and $\mu-\Lambda$ relation for the unique TC microphysics in China are obtained. These new relations are useful for improving the accuracy of quantitative precipitation estimation and model microphysical parameterizations for landfalling TCs over China. Results from polarimetric radar observations of landfalling TCs reveal that the kinematic structure of convective cells in inner rainbands is similar to that of principal rainband over the ocean, while convection in outer rainbands exhibits a squall-like structure. Warmrain processes are dominated in inner rainbands, while particle growth in outer rainbands is dominated by ice-phase cloud microphysical processes. These results demonstrate the importance of strong interactions between kinematic and microphysical processes in rainbands of landfalling TCs.
Several new data assimilation and forecasting systems have been developed under the support of this project, including a multiple-ensemble-based data assimilation and application system with a new sample optimization scheme, a new dual-linear polarization radar data assimilation technique, a rapid cycling radar data assimilation and nowcasting system, a typhoon regional assimilation and prediction system T-RAPS, and several new methods to assess impacts induced by landfalling TCs in China. These developments provide more powerful supports not only to operational TC forecasts but also to research on landfalling TCs. They will substantially enhance the ability of operational TC forecasts, leading to improved forecast skills for landfalling TCs in China. These developments can also be adopted by other countries experiencing impact of landfalling TCs. In addition, a high-resolution reanalysis system has been planned to provide high-quality reanalysis data for all 24 targeted landfalling TCs to research community to further investigate landfalling TC processes.

The LTCRP will end in 2019, but the China Science Field Experiment in South China will continue for summer monsoon heavy precipitation and landfalling TCs. The observations for targeted TCs will still focus on the fine structure of landfalling TCs and the related boundary layer and cloud microphysical processes. All data will be integrated into the database TCLPFieldSED developed under this project and will be available to research community. So far only part of the data have been used in process studies. We plan to make full use of these observational data to various follow-up research and applications. We will continue to focus on documenting the fine structure of landfalling TCs and studying the involved dynamical and physical processes, in particular the turbulent boundary layer and cloud/precipitation processes. The revealed cloud microphysical properties from this project will be extensively used to improve cloud microphysical parameterizations and to verify cloud/precipitation processes in numerical model simulations/forecasts. The CMA will continue to support projects on improving the existing data assimilation and numerical forecasting systems and developing new techniques to make full use of observational data collected in field campaigns for landfalling TCs.

We also encourage and develop international collaborations in various aspects as follow-up activities of the LTCRP. Based on this project, Chinese scientists have launched an international project on landfalling TC precipitation, which has been developed into an international Research and Development 
Project (RDP) of the World Meteorological Organization (WMO) World Weather Research Programme (WWRP). The project, named UPDRAFT, which stands for Understanding and Prediction of Rainfall Associated with Landfalling Typhoon, has been ongoing for more than three years since 2015. The project is led by experts from the School of Atmospheric Sciences of Nanjing University, with participating scientists from the United States, Australia, and China. In the future, new possible international partnerships are expected to be developed to use the data to improve understanding and predicting landfalling TCs.

ACKNOWLEDGMENTS. This study has been supported by the National Basic Research and Development Project (973 program) of China under Contract 2015CB452800. The authors are grateful to Mr. Kai-Kwong Hon and Drs. Zhe-Min Tan, Qingqing Li, Xudong Liang, Leiming Ma, Jie Ming, Xin Qiu, Jia Liang, Xiaotu Lei, and Xuyang Ge for actively participating in this research project and for helpful comments on an earlier version of the manuscript. They also thank three anonymous reviewers for constructive review comments that significantly helped improve the manuscript. The NCEP GFS final analysis final data, the JTWC best track TC data, and the CMA best track TC data are obtained from https://rda.ucar.edu/datasets /ds083.2, www.metoc. navy.mil/jtwc/jtwc.html, and http:// tcdata.typhoon.org.cn/zjljsjj_sm.html, respectively.

\section{REFERENCES}

Barker, D., W. Huang, Y. Guo, A. Bourgeois, and Q. Xiao, 2004: A three-dimensional variational data assimilation system for MM5: Implementation and initial results. Mon. Wea. Rev., 132, 897-914, https://doi.org/10.1175/1520-0493(2004)132<0897 :ATVDAS $>2.0 . \mathrm{CO} ; 2$

Bi, X., and Coauthors, 2015: Observed drag coefficients in high winds in the near offshore of the South China Sea. J. Geophys. Res. Atmos., 120, 6444-6459, https:// doi.org/10.1002/2015JD023172.

Bister, M., and K. A. Emanuel, 1998: Dissipative heating and hurricane intensity. Meteor. Atmos. Phys., 65, 233-240, https://doi.org/10.1007/BF01030791.

Byrne, D., and J. A. Zhang, 2013: Height-dependent transition from 3-D to 2-D turbulence in the hurricane boundary layer. Geophys. Res. Lett., 40, 1439-1442, https://doi.org/10.1002/grl.50335.

Cha, D.-H., and Y. Wang, 2013: A dynamical initialization scheme for real-time forecasts of tropical cyclones using the WRF Model. Mon. Wea. Rev., 141, 964-986, https://doi.org/10.1175/MWR-D-12-00077.1.
Chang, W.-Y., T.-C. C. Wang, and P.-L. Lin, 2009: Characteristics of the raindrop size distribution and drop shape relation in typhoon systems in the western Pacific from the $2 \mathrm{D}$ video disdrometer and NCU C-band polarimetric radar. J. Atmos. Oceanic Technol., 26, 1973-1993, https://doi.org/10.1175 /2009JTECHA1236.1.

Chen, H.-Y., H. Yu, G.-J. Ye, M. Xu, and Q.-Z. Yang, 2019: Return period and the trend of extreme disastrous rainstorm events in Zhejiang Province. $J$. Trop. Meteor., 25, 192-200, https://doi.org/10.16555 /j.1006-8775.2019.02.006.

Chen, L., Y. Li, and Z. Cheng, 2010: An overview of research and forecasting on rainfall associated with landfalling tropical cyclones. Adv. Atmos. Sci., 27, 967-976, https://doi.org/10.1007/s00376-010-8171-y. Chen, P.-Y., X.-T. Lei, and M. Ying, 2013: Introduction and application of a new comprehensive assessment index for damage caused by tropical cyclones. Trop. Cyclone Res. Rev., 2, 176-183, https://doi.org/10.6057 /2013TCRR03.05.

Chen, W.-F., S. L. Cutter, C. T. Emrich, and B.-J. Shi, 2013: Measuring social vulnerability to natural hazards in the Yangtze River Delta region, China. Int. J. Disaster Risk Sci., 4, 169-181, https://doi.org/10.1007 /s13753-013-0018-6.

Davidson, N. E., and Coauthors, 2014: ACCESS-TC: Vortex specification, 4DVAR initialization, verification, and structure diagnostics. Mon. Wea. Rev., 142, 1265-1289, https://doi.org/10.1175/MWR -D-13-00062.1.

Dong, L., and F. Zhang, 2016: OBEST: An observation-based ensemble subsetting technique for tropical cyclone track prediction. Wea. Forecasting, 31, 57-70, https://doi.org/10.1175/WAF-D-15-0056.1.

Duan, Y., L. Chen, J. Liang, Y. Wang, L. Wu, X. Cui, L. Ma, and Q. Li, 2014: Research progress in the unusual variations of typhoons before and after landfalling. Acta Meteor. Sin., 72, 969-986.

Elsberry, L. E., L.-S. Chen, J. Davidson, R. Rogers, Y. Wang, and L. Wu, 2013: Advances in understanding and forecasting rapidly changing phenomena in tropical cyclones. Trop. Cyclone Res. Rev., 2, 13-24.

Gao, W. H., F. S. Zhao, Z. J. Hu, and X. Feng, 2011: A two-moment bulk microphysics coupled with a mesoscale model WRF: Model description and first results. Adv. Atmos. Sci., 28, 1184-1200, https://doi.org /10.1007/s00376-010-0087-z.

—, C.-H. Sui, J. Fan, Z. Hu, and L. Zhong, 2016: A study of cloud microphysics and precipitation over the Tibetan Plateau by radar observations and cloud-resolving model simulations, J. Geophys. Res. Atmos., 121, 13735-13752, https://doi.org/10.1002/2015JD024196. 
Houtekamer, P. L., and F. Zhang, 2016: Review of the ensemble Kalman filter for atmospheric data assimilation. Mon. Wea. Rev., 144, 4489-4532, https://doi .org/10.1175/MWR-D-15-0440.1.

Houze, R. A., Jr., 2010: Clouds in tropical cyclones. Mon. Wea. Rev., 138, 293-344, https://doi.org/10 $.1175 / 2009$ MWR2989.1.

Li, J., Y. Gao, and Q. Wan, 2018: Sample optimization of ensemble forecast to simulate a tropical cyclone using the observed track. Atmos.-Ocean, 56, 112-128, https://doi.org/10.1080/07055900.2018.1500881.

Li, Q.-Q., and Y. Wang, 2012: A comparison of inner and outer spiral rainbands in a numerically simulated tropical cyclone. Mon. Wea. Rev., 140, 2782-2805, https://doi.org/10.1175/MWR-D-11-00237.1.

Liu, H., Y. Wang, J. Xu, and Y. Duan, 2018: A Dynamical initialization scheme for tropical cyclones under the influence of terrain. Wea. Forecasting, 33, 641-659, https://doi.org/10.1175/WAF-D-17-0139.1.

Lu, Y., F. M. Ren, and W. J. Zhu, 2018: Risk zoning of typhoon disasters in Zhejiang Province, China. Nat. Hazards Earth Syst. Sci., 18, 2921-2932, https://doi.org /10.5194/nhess-18-2921-2018.

Ming, J., and J. A. Zhang, 2018: Direct measurements of momentum flux and dissipative heating in the surface layer of tropical cyclones during landfalls. $J$. Geophys. Res. Atmos., 123, 4926-4938, https://doi.org /10.1029/2017JD028076.

—, — - R. F. Rogers, F. D. Marks, Y. Wang, and N. Cai, 2014: Multiplatform observations of boundary layer structure in the outer rainbands of landfalling typhoons. J. Geophys. Res. Atmos., 119, 7799-7814, https://doi.org/10.1002/2014JD021637.

Morrison, H., J. A. Curry, and V. I. Khvorostyanov, 2005: A new double moment microphysics parameterization for application in cloud and climate models. Part I: Description. J. Atmos. Sci., 62, 1665-1677, https:// doi.org/10.1175/JAS3446.1.

Qi, L., H. Yu, and P. Chen, 2014: Selective ensemble-mean technique for tropical cyclone track forecast by using ensemble prediction systems. Quart. J. Roy. Meteor. Soc., 140, 805-813, https://doi.org/10.1002 /qj.2196.

Tallapragada, V., and Coauthors, 2015: Forecasting tropical cyclones in the western North Pacific basin using the NCEP operational HWRF: Real-time implementation in 2012. Wea. Forecasting, 30, 1355-1373, https://doi.org/10.1175/WAF-D-14-00138.1.

Tang, J., D. Byrne, J. A. Zhang, Y. Wang, X.-T. Lei, D. Wu, P.-Z. Fang, and B.-K. Zhao, 2015: Horizontal transition of turbulent cascade in the near-surface layer of tropical cyclones. J. Atmos. Sci., 72, 49154925, https://doi.org/10.1175/JAS-D-14-0373.1.
Tokay, A., P. G. Bashor, E. Habib, and T. Kasparis, 2008: Raindrop size distribution measurements in tropical cyclones. Mon. Wea. Rev., 136, 1669-1685, https:// doi.org/10.1175/2007MWR2122.1.

Wang, H., Q. Wan, J. Yin, and W. Ding, 2016: Application of the dual-polarization radar data in numerical model: Construction of simulator (in Chinese with English abstract). Acta. Meteor. Sin., 74, 229-243, https://doi.org/10.11676/qxxb2016.017.

Wang, H., Y. Wang, J. Xu, and Y.-H. Duan, 2019: The axisymmetric and asymmetric aspects of the secondary eyewall formation in a numerically simulated tropical cyclone under idealized conditions on an $f$-plane. J. Atmos. Sci., 76, 357-378, https://doi.org/10.1175 /JAS-D-18-0130.1.

Wang, M., K. Zhao, M. Xue, G. Zhang, S. Liu, L. Wen, and G. Chen, 2016: Precipitation microphysics characteristics of a Typhoon Matmo (2014) rainband after landfall over eastern China based on polarimetric radar observations. J. Geophys. Res. Atmos., 121, 12 415-12 433, https://doi.org/10.1002 /2016JD025307.

__ _ _ W. C. Lee, and F. Zhang, 2018: Microphysical and kinematic structure of convective-scale elements in the inner rainband of Typhoon Matmo (2014) after landfall. J. Geophys. Res. Oceans, 123, 6549-6564, https://doi.org/10.1029/2018JD028578.

Wang, Y., 1999: A triply-nested movable mesh tropical cyclone model with explicit cloud microphysics. BMRC Research Rep. 74, Bureau of Meteorology Research Center, $81 \mathrm{pp}$.

Wang, Y., 2001: An explicit simulation of tropical cyclones with a triply nested movable mesh primitive equation model: TCM3. Part I: Model description and control experiment. Mon. Wea. Rev., 129, 1370-1394, https://doi.org/10.1175/1520-0493(2001)129<1370 :AESOTC $>2.0 . C O ; 2$.

Wen, G., H. Xiao, H. Yang, Y. Bi, and W. Xu, 2017: Characteristics of summer and winter precipitation over northern China. Atmos. Res., 197, 390-406, https:// doi.org/10.1016/j.atmosres.2017.07.023.

Wen, J., and Coauthors, 2017: Evolution of microphysical structure of a subtropical squall line observed by a polarimetric radar and a disdrometer during OPACC in Eastern China. J. Geophys. Res. Atmos., 122, 8033-8050, https://doi.org/10.1002/2016JD026346.

Wen, L., and Coauthors, 2018: Drop size distribution characteristics of Seven Typhoons in China. J. Geophys. Res. Atmos., 123, 6529-6548, https://doi. org/10.1029/2017JD027950.

$\mathrm{Wu}, \mathrm{D}$., and Coauthors, 2018: Kinematics and microphysics of convection in the outer rainband of Typhoon Nida (2016) revealed by polarimetric 
radar. Mon. Wea. Rev., 146, 2147-2159, https://doi. org/10.1175/MWR-D-17-0320.1.

Xiao, Y.-J., Y.-F. Wan, and Z.-B. Wang, 2016: Quality control of dual PRF velocity data for Doppler weather radars (in Chinese). Plateau Meteor., 35, 1112-1122.

Xie, Y., S. Koch, J. McGinley, S. Albers, P. E. Bieringer, M. Wolfson, and M. Chan, 2011: A space-time multiscale analysis system: A sequential variational analysis approach. Mon. Wea. Rev., 139, 1224-1240, https://doi.org/10.1175/2010MWR3338.1.

Zhang, C.-X., and Y. Wang, 2017: Projected future changes of tropical cyclone activity over the western North and South Pacific in a $20-\mathrm{km}$-mesh regional climate model. J. Climate, 30, 5923-5941, https://doi .org/10.1175/JCLI-D-16-0597.1.

Zhang, F., Y. Weng, J. A. Sippel, Z.-Y. Meng, and C. H. Bishop, 2009: Cloud resolving hurricane initialization and prediction through assimilation of Doppler radar observations with an ensemble Kalman filter. Mon. Wea. Rev., 137, 2105-2125, https://doi .org/10.1175/2009MWR2645.1.

Zhang, F., Z. Shen, J. Li, X. Zhou, and L. Ma, 2013: Analytical delta-four-stream doubling-adding method for radiative transfer parameterizations. J. Atmos. Sci., 70, 794-808, https://doi.org/10.1175 /JAS-D-12-0122.1.

— , K. Wu, J. Li, Q. Yang, J. Zhao, and J. Li, 2016: Analytical infrared delta-four-stream adding method from invariance principle. J. Atmos. Sci., 73, 4171-4188, https:/doi.org/10.1175/JAS-D-15-0317.1.

—, K. Wu, P. Liu, X.-W. Jing, and J.-N. Li, 2017: Accounting for Gaussian quadrature in four-stream radiative transfer algorithms. J. Quan. Spectr. Rad. Transfer, 192, 1-13, https://doi.org/10.1016/j.jqsrt 2017.01.040.

— , K. Wu, J.-N. Li, H. Zhang, and S. Hu, 2018: Radiative transfer in the region with solar and infrared spectra overlap. J. Quan. Spectr. Rad. Transfer, 219, 366-378, https://doi.org/10.1016/j.jqsrt .2018.08.025.
Zhang, G. F., 2016: Weather Radar Polarimetry. CRC Press, 304 pp.

Zhang, J. A., R. F. Rogers, D. S. Nolan, and F. D. Marks Jr., 2011: On the characteristic height scales of the hurricane boundary layer. Mon. Wea. Rev., 139, 25232535, https://doi.org/10.1175/MWR-D-10-05017.1.

—, D. S. Nolan, R. F. Rogers, and V. Tallapragada, 2015: Evaluating the impact of improvements in the boundary layer parameterization on hurricane intensity and structure forecasts in HWRF. Mon. Wea. Rev., 143, 3136-3155, https://doi.org/10.1175 /MWR-D-14-00339.1.

—, R. F. Rogers, and V. Tallapragada, 2017: Impact of parameterized boundary layer structure on tropical cyclone rapid intensification forecasts in HWRF. Mon. Wea. Rev., 145, 1413-1426, https://doi .org/10.1175/MWR-D-16-0129.1.

Zhang, Q., L. Wu, and Q. Liu, 2009: Tropical cyclone damages in China 1983-2006. Bull. Amer. Meteor. Soc., 90, 489-496, https://doi.org/10.1175/2008BAMS2631.1.

Zhang, X.-H., Y.-H. Duan, Y. Wang, N. Wei, and H. Hu, 2017: A high-resolution simulation of Super typhoon Rammasun (2014). Part I: Model verification and surface energetics analysis. Adv. Atmos. Sci., 34, 757-770, https://doi.org/10.1007/s00376-017-6255-7.

Zhao, K., and Coauthors, 2017: Doppler radar analysis of a tornadic miniature supercell during the landfall of Typhoon Mujigae (2015) in South China. Bull. Amer. Meteor. Soc., 98, 1821-1831, https://doi.org/10.1175 /BAMS-D-15-00301.1.

Zhao, Z.-K., C.-X. Liu, Q. Li, G.-F. Dai, Q.-T. Song, and W.-H. Lv, 2015: Typhoon air-sea drag coefficient in coastal regions. J. Geophys. Res. Oceans, 120, 716-727, https://doi.org/10.1002/2014JC010283.

Zhu, L., and Coauthors, 2016: Prediction and predictability of high-impact western Pacific landfalling Tropical Cyclone Vicente (2012) through convection-permitting ensemble assimilation of doppler radar velocity. Mon. Wea. Rev., 144, 21-43, https:// doi.org/10.1175/MWR-D-14-00403.1. 